\title{
Spectroscopy of Biological Molecules
}

Theory and Applications - Chemistry, Physics, Biology, and Medicine

edited by

Camille Sandorfy

and

Theophile Theophanides

Department of Chemistry, University of Montreal, Montreal, Quebec, Canada

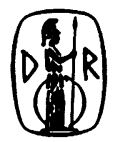

D. Reidel Publishing Company

Dordrecht / Boston / Lancaster

Published in cooperation with NATO Scientific Affairs Division 
TABLE OF CONTENTS

I. THEORETICAL OVERVIEW

ENERGY BANDS IN DNA

J. J. Ladik

H-BOND CHARGE-RELAY CHAINS IN MULTI-HEME CYTOCHROMES AND OTHER BIOMOLECULES

G. Del Re

HYDROGEN BONDING-THEORETICAL AND SPECTROSCOPIC ASPECTS

D. Hadži

HYDROGEN BONDS IN BIOLOGICAL STRUCTURE AND MECHANISM

D. Hadži

II. RAMAN AND INFRARED STUDIES OF THE STRUCTURE AND DYNAMICS OF NUCLEIC ACIDS AND PROTEINS

RAMAN STUDIES ON DINUCLEOSIDE MONOPHOSPHATES

E. D. Schmid and V. Gramlich

MOLECULAR INTERACTION BETWEEN NUCLEIC ACIDS AND ALKYLATING AGENTS BY RAMAN SPECTROSCOPY

A. Bertoluzza

RAMAN AND FT-IR SPECTROSCOPY OF DRUG-BIOLUGICAL TARGET INTERACTIONS IN VITRO AND IN VIVO

M. Manfait, T. Theophanides, A. J. P. Alix and

P. Jeannesson

SPECTROSCOPIC PROPERTIES OF METAL-NUCLEOTIDE AND METAL-NUCLEIC ACID INTERACTIONS

T. Theophanides and H. A. Tajmir-Riahi

CONFORMATION AND DYNAMICS OF NUCLEIC ACIDS AND PROTEINS FROM LASER RAMAN SPECTROSCOPY

W. L. Peticolas

STRUCTURAL TRANSITIONS IN DNA $(\mathrm{A}, \mathrm{B}, \mathrm{Z})$ STUDIED BY IR SPECTROSCOPY

E. Taillandier, J. Liquier, J. Taboury, and M. Ghomi 
RAMAN SPECTROSCOPY OF BIOMATERIALS ACTING AS BONE PROSTHESIS

A. Bertoluzza

III. NMR SPECTROSCOPY AND ITS APPLICATIONS

TEACHING THE NEW NMR: A COMPUTER-AIDED INTRODUCTION TO THE DENSITY MATRIX FORMALISM OF MULTIPULSE SEQUENCES

G. D. Mateescu and A. Valeriu

SOLUTION AND SOLID STATE C-13 AND N-15 NMR STUDIES OF VISUAL PIGMENTS AND RELATED SYSTEMS: RHODOPSIN AND BACTERIORHODOPSIN

G. D. Mateescu, E. W. Abrahamson, J. W. Shriver, W. Copan,

D. Muccio, M. Iqbal and V. Waterhous

HIGH RESOLUTION ${ }^{1}$ H NMR STUDIES OF MONONUCLEOTIDES WITH METALS

T. Theophanides and M. Polissiou

IV. THE MECHANISM OF VISION PLANT PIGMENTS

RESONANCE RAMAN DETERMINATION OF RETINAL CHROMOPHORE STRUCTURE IN BACTERIORHODOPSIN

R. A. Mathies

STRUCTURAL AND KINETIC STUDIES OF BACTERIORHODOPSIN BY RESONANCE RAMAN SPECTROSCOPY

T. Alshuth, P. Hildebrandt, and M. Stockburger

STATIC AND TIME-RESOLVED INFRARED DIFFERENCE SPECTROSCOPY APPLIED TO RHODOPSIN AND BACTERIORHODOPSIN

F. Siebert

INTERMEDIATE STATES IN VISION

P. M. Rentzepis

CORRELATION OF CELLULAR AND MOLECULAR CHANGES IN VISUAL PHOTORECEPTORS BY LIGHT SCATTERING RELAXATION PHOTOMETRY

E. W. Abrahamson, T. J. Borys, B. D. Gupta, R. Jones,

R. Uh 1 , A. Geistefer, and S. Deshpande

SPECTROSCOPY OF PLANT TETRAPYRROLES IN VITRO AND IN VIVO

H. Scheer

PREPARATION OF ${ }^{2} \mathrm{H}$ AND ${ }^{13} \mathrm{C}$ LABELED RETINALS

$\mathrm{J}$. Lugtenburg

AN INTRODUCTION TO TWO-PHOTON SPECTROSCOPY

R. R. Birge

TWO-PHOTON SPECTROSCOPY OF BIOLOGICAL MOLECULES

R. R. Birge, B. M. Pierce, and L. P. Murray 


\section{SPECTROSCOPY OF MEMBRANES}

MOLECULAR STRUCTURE OF THE GRAMICIDIN TRANSMEMBRANE CHANNEL: UTILIZATION OF CARBON-13 NUCLEAR MAGNETIC RESONANCE, ULTRAVIOLET ABSORPTION, CIRCULAR DICHROISM AND INFRARED SPECTROSCOPIES

$$
\text { D. W. Urry }
$$

IONIC MECHANISMS AND SELECTIVITY OF THE GRAMICIDIN TRANSMEMBRANE CHANNEL: CATION NUCLEAR MAGNETIC RESONANCE, DIELECTRIC RELAXATION, CARBON-13 NUCLEAR MAGNETIC RESONANCE, AND RATE THEORY CALCULATION OF SINGLE CHANNEL CURRENTS

R. W. Urry

IN SITU MONITORING OF MEMBRANE-BOUND REACTIONS BY KINETIC LIGHT-SCATTERING

A. Schleicher and K. P. Hofmann

FOURIER TRANSFORM INFRARED SPECTROSCOPY AS A PROBE OF BIOMEMBRANE STRUCTURE

H. H. Mantsch

INVESTIGATIONS ON BIOLOGICALLY IMPORTANT HYDROGEN BONDS

C. Sandorfy, R. Buchet, and P. Mercier

VI. RECENT ADVANCES IN SPECTROSCOPIC TECHNIQUES

A REVIEW OF THE FOURIER TRANSFORM NEAR INFRARED SPECTROMETER FOR THE DETERMINATION OF NON-METALS IN ORGANIC COMPOUNDS BY ATOMIC EMISSION FROM AN ATMOSPHERIC PRESSURE ARGON INDUCTIVELY COUPLED PLASMA

A. J. J. Schleisman, J. A. Graham, R. C. Fry, and W. G. Fateley

RAMAN MICROPROBE AND MICROSCOPE. TIME RESOLVED RAMAN TECHNIQUES

M. Delhaye

FAR-INFRARED SPECTROSCOPY OF BIOMOLECULES

L. Genze1, L. Santo, and S. C. Shen

PICOSECOND RELAXATIONS IN HAEMOGLOBIN, LYSOZYME, AND POLY-L-ALANINE OBSERVED BY MM-WAVE SPECTROSCOPY

L. Genzel, F. Kremer, A. Poglitsch, and G. Bechtold

AUTHOR INDEX

SUBJECT INDEX 


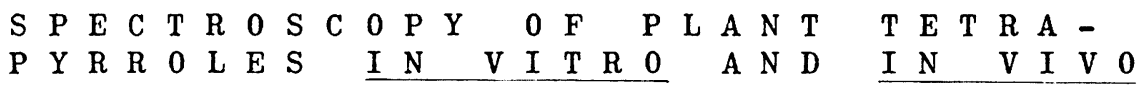

\author{
Hugo Scheer \\ Botanisches Institut der Universität \\ Menzinger Straße 67 \\ 8000 München 19 F.R. Germany
}

\title{
$\underline{\text { ABSTRACT }}$
}

The spectroscopy of chlorophylls and biliproteins is discussed with examples selected from recent investigations. These include the structure elucidation of the phytochrome Pfr chromophore and the current status of the work on chlorophyll-RC I, work on the biosynthesis of chlorophylls by non-invasive techniques, studies on the in situ structure of chlorophylls and biliprotein chromophores, energy transfer studies in photosynthetic antenna systems.

\section{Abbreviations:}

Chl $=$ Chlorophyll, Bchl $=$ Bacteriochlorophyll, Phe $=$ Pheophytin, Bphe = Bacteriopheophytin, Mephe = Methylpheophor bide, Bmephe $=$ Bacteriomethylpheophorbide, $\underline{\mathrm{PC}}=$ Phycocyanin $\mathrm{Pr}$ and $\underline{\mathrm{Pfr}}=$ Phytochrome in the red and far-red absorbing form, respectively, uv-vis-nir = absorption in the ultraviolet, visible and near infrared spectral range, $C D=$ circular dichroism, FDMR = fluorescence detected magnetic resonance, $N M R=$ nuclear magnetic resonance, $E S R=$ electron spin resonance, ENDOR = electron nuclear double resonance, HPLC = high performance liquid chromatography.

Acknowledgements: The cited work of the author was supported by the Deutsche Forschungsgemeinschaft, Bonn and by the Universitätsgesellschaft, München. 


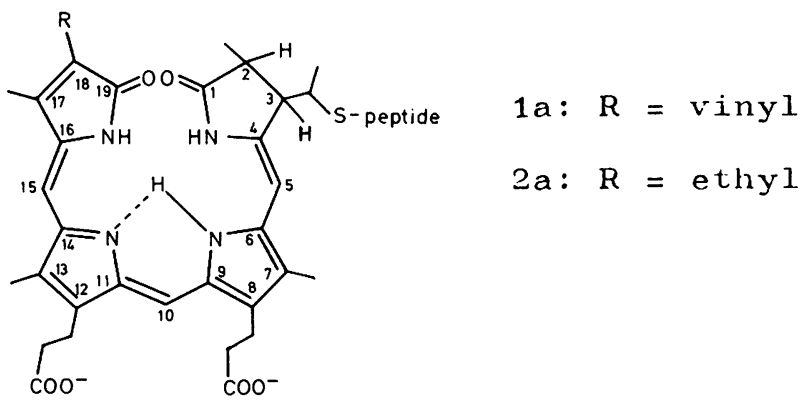

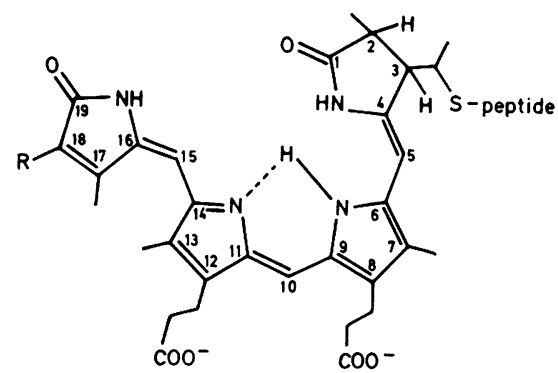

$1 b, 2 b$

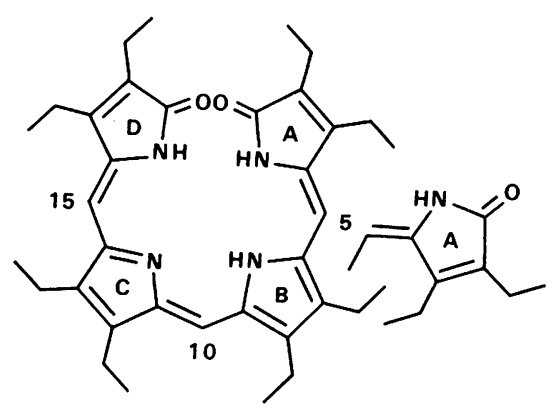

$3 a$

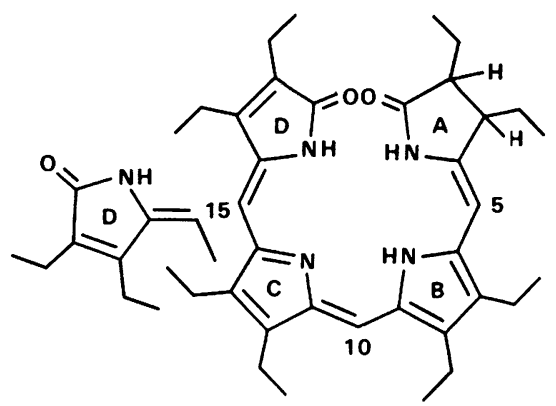

$4 b$

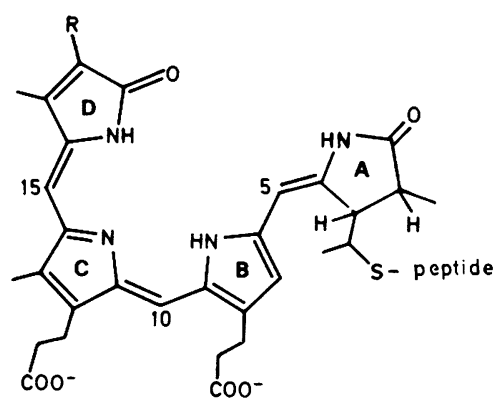

$1 c, 2 c$ 


\section{A : INTRODUCTION}

Spectroscopic techniques have become increasingly important in biological studies. This is mainly due to great improvements in their sensitivity and selectivity, but also to advancements in the underlying theories which made less ambigous interpretations possible. The technical details of these improvements are beyond the scope of this talk and have in part been dealt with by other authors of this summer school. In view of the vast amount of material on the spectroscopy of plant tetrapyrroles, I have also not tried to give a complete review, but have rather focused on comparatively few examples which are meant to illustrate the current approaches, potentials and limitations of some selected methods. I apologize for any undue bias in this selection.

Plant tetrapyrroles comprise the chlorophylls and the biliproteins serving as photoreceptor pigments, the cytochromes functioning in the electron transport of photosynthesis and respiration, the sirohemes and cobalamine(s) acting as cofactors in several important enzymes, and also the biosynthetic precursors and degradation products of all these pigments. I shall only deal with recent investigations on chlorophylls, biliproteins and metabolically related structures. The chosen examples focus on two pects. The first is the structure elucidation of isolated or at least enriched compounds (section B). The second is the spectroscopy of increasingly complex systems up to whole organelles or organisms (section C). It has been used study the in situ structure of the pigments, but also to study their biosynthesis and to investigate the interrelations among the different pigment molecules.

\section{B: SPECTROSCOPY OF ISOLATED PIGMENTS}

Improved separation techniques have recently allowed the isolation of many new plant tetrapyrroles and provided evidence for an even larger number of pigments present only in small amounts besides the major chlorophylls, e.g. $\underline{\mathrm{Chl}}$ a and $\mathrm{Chl}$ b in plants and $\mathrm{Bchl}$ a, $\underline{\mathrm{b}}, \underline{\mathrm{c}}$ and $\mathrm{d}$ in bacteria. Optical spectroscopy, in particūlar unv-vis-nir absorption, is the most sensitive and rapid technique to classify among the different pigments. Useful structural hints can be obtained from comparison with pigments of known structure, but the method is unable to provide more details. The two major methods for structure elucidation 


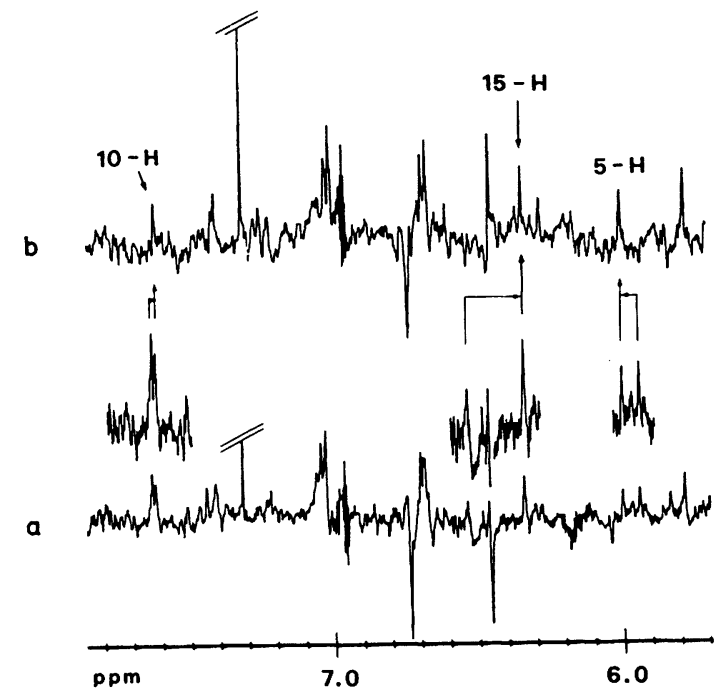

Fig. 1: ${ }^{1}$ H-NMR-epectra $(500 M H z)$ of phytochrome chromopeptidea in the methine regionc. (a) 1:1mixture of $\operatorname{Pfr}(1 \mathrm{~b})$ and $\operatorname{Pr}$ (1a) peptide obtained from the photoequilibrium mixture of Pfr. (b) The came cample after irradiation $\overline{\text { with }}$ white light. The paira of linea acaociated with the two forme collapee to a eingle line of the $\mathrm{Z}, \mathrm{Z}, \mathrm{Z}$-peptide ( $\mathrm{Pr}=1 \mathrm{a})$, the largect chift ic obcerved at the cite of icomerication $(C-15)$.

From Thümiler et al. (7).
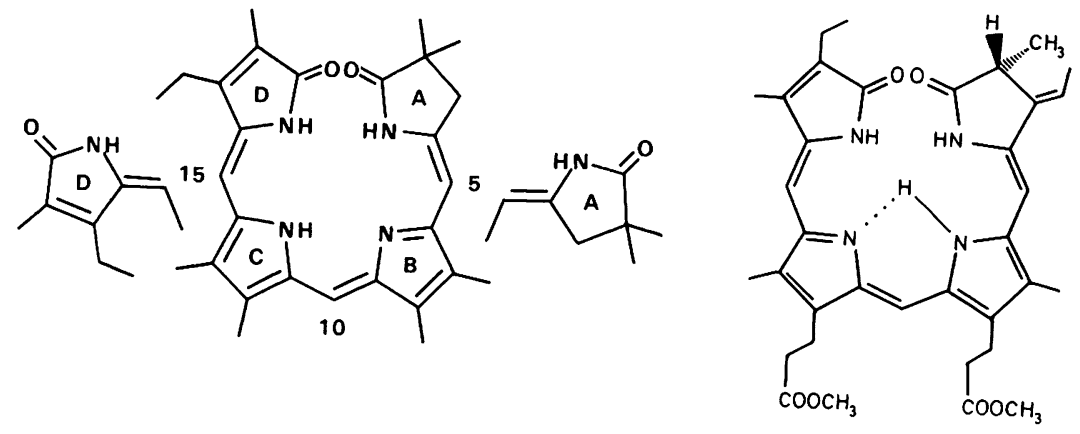
are NMR and mass spectroscopy, which are both well established, and have been considerably improved recently. The limiting factor in NMR spectroscopy is its sensitivity. It is now sufficientlyincreased to allow work in the $\mathrm{ug}$ range, which puts stringent requirements on the sample preparation and purity. The limiting factor of mass spectroscopy has been the ionisation without alteration. It has also been considerably improved recently by new ionisation techniques, which now allow the direct analysis of e.g. underivatized chlorophylls. Both methods are most useful in conjunction with suitable chemical correlation methods. Two structures are chosen to illustrate their potentials.

\section{B. a: CHROMOPHORE OF PHYTOCHROME IN THE Pfr FORM}

The biliprotein, phytochrome is the only photomorphogenetic pigment in plants of which some structural details are known. It is a photoreversibly photochromic pigment, with one form, $\mathrm{Pr}$, absorbing maximally around $660 \mathrm{~nm}$, and the other, Pfr, around $730 \mathrm{~nm}$ in the long-wavelength spectral region. Phytochrome occurs only in small amounts and concentrations in plants, and its photochromic properties have been used as analytical tool during the isolation. The similarities in the optical absorption spectra of $\mathrm{Pr}$ and the readily accessible phycobiliprotein, phycocyanin ( $\underline{P C})$, were substantial in assigning a bile pigment structure, too, to the chromophore of the former (see RÜDIGER and SCHEER (1) for leading references). The detailed structure analysis of phytochrome was complicated by the rather stable thioether bond between the chromophore and the apoprotein, which precluded a chromophore cleavage without alterations of the chromophore, and also by the poor accessibility of phytochrome. The same chemical degradation techniques, developed with $\underline{P C}$ and then applied to phytochrome (2) provided together with studies on model pigments like $3,4(3)$ and with the total synthesis of bile pigments related to the native pigments (e.g. 5 , refs. 4) the structures 1 a and 2 a for the chromophores of $\underline{\mathrm{Pr}}$ and $\underline{\mathrm{PC}}$, respectively. The evidence for the 18-vinyl group in 1 was, however, only circumstantial (5).

The same structures and a proof of the latter substituent have been arrived at by proton NMR of bilipeptides from the two pigments (6). The NMR spectrum of linear tetrapyrroles covers the spectral range between $\delta=1$ and $8 \mathrm{ppm}$. There is a considerable overlap with the NMR lines of the peptide moiety of these chromopeptides. The structure analysis was nonetheless possible by the use of high-field NMR spectrometers ( $360 \mathrm{MHz}$ in the particular case). This 
Table 1: Incremental chemical chifta $(\Delta)$ of the methine proton NMR aignals in Z,E-iaomeric bilindiones. $\Delta($ in $\mathrm{ppm})$ is given as $\delta_{\mathrm{E}}-\delta_{\mathrm{Z}}$

\begin{tabular}{|c|c|c|c|c|c|}
\hline Compound & $5-\mathrm{H}$ & $15-\mathrm{H}$ & $10-\mathrm{H}$ & colvent & ref. \\
\hline $\begin{array}{l}\text { phytochrome } \\
\text { chromophore } \\
(\underline{\underline{\underline{b}}}=\operatorname{minus} \underline{\underline{a}})\end{array}$ & $-0,057$ & $+0,195$ & $+0,012$ & $\begin{array}{l}\text { acetone- } d_{6} / \\
\mathrm{H}_{2} \mathrm{O} / \mathrm{CF}_{3} \mathrm{COOH}\end{array}$ & ( 7 ) \\
\hline $\begin{array}{l}\text { phycocyanin } \\
\text { chromophore } \\
(\underline{=}=\underline{b} \text { minus } 2 a)\end{array}$ & $-0,056$ & $+0,195$ & $+0,018$ & $\begin{array}{l}\text { acetone- } d_{6} / \\
\mathrm{H}_{2} \mathrm{O} / \mathrm{CF}_{3} \mathrm{COOH}\end{array}$ & $(7)$ \\
\hline $\begin{array}{l}\text { octaethyl- } \\
\text { bilindione } \\
\quad(\underline{\underline{3}}=\underline{\mathrm{b}} \text { minus } \underline{\underline{3}} \mathrm{a})\end{array}$ & 0 & $+0,27$ & 0 & $\mathrm{CDCl}_{3} / \mathrm{CF}_{3} \mathrm{COOH}$ & (8) \\
\hline 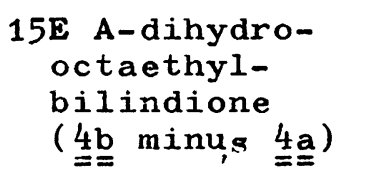 & 0 & $+0,23$ & 0 & $\mathrm{CDCl}_{3}$ & (8) \\
\hline $\begin{array}{l}\text { 15E A-dihydro- } \\
\text { bilindione } \\
\text { (unsubstituted } \\
\text { Ring A) }\end{array}$ & $-0,07$ & $+0,23$ & $-0,01$ & $\mathrm{CDCl}_{3}$ & $(4 b)$ \\
\hline $\begin{array}{c}\text { 15E 3-dihydro- } \\
7,8,12,13,18- \\
\text { methyl-2-di- } \\
\text { methyl-17-ethy } \\
\text { bilindione } \\
(\text { bb minus } \underline{=} \text { a) }\end{array}$ & $-0,09$ & $+0,20$ & $-0,03$ & $\mathrm{CDCl}_{3}$ & (9) \\
\hline $\begin{array}{l}\text { 4E-dihydro- } \\
7,8,12,13,18- \\
\text { methyl-2-di- } \\
\text { methyl-17-ethy } \\
\text { bilindione } \\
\text { ( } 6 \text { c minus } 6 \text { a })\end{array}$ & $1-$ & $+0,08$ & $+0,26$ & $\mathrm{CDCl}_{3}$ & (9) \\
\hline
\end{tabular}


did not only allow for sufficient resolution to separate the overlapping lines from the peptide and the chromophore, but gave also the necessary increased sensitivity required for the work with phytochrome. An assignment of all chromophore proton signals in the PC-peptide was achieved by comparison with a synthetic peptide of the identical sequence, but lacking the chromophore. This was in turn the basis for the assignment of the chromophore derived signals (including those of the 18-vinyl group), in the Pr peptide, leading independently to structure 1 a.

The structure elucidation of the Pfr chromophore posed additional problems. Pfr peptides revert spontaneously to the $\mathrm{Pr}$ form. This reversion is pH-dependent and sufficiently retarded only at moderately low $\mathrm{pH}$. The preparation of Pfr peptides required therefore peptic digestion and subsequent work-up under conditions which maintained a $\mathrm{pH} \approx 3$ throughout. This work-up can be done in protonated solvents, but an exchange with deuterated solvent at the last chromatographic step is necessary for NMR (7). Unfortunate$1 y$, at least one $(5-H)$ of the three methine protons is readily exchangeable, too, with deuterium under acidic conditions. Such an exchange was untolerable, because the methine signals were essential to differentiate between the discussed mechanisms in the $\mathrm{Pr}$ - Pfr interconversion, e.g. a redox mediated substitution and a $\mathrm{Z}, \mathrm{E}-\mathrm{isomerisation.}$

The extensive tests to circumvent these obstacles made again use of the readily accessible $\underline{P C}$ and of synthetic bilidiones like 3 and 4 as models for phytochrome, which were used to optimize the measuring conditions. It could be shown, that a mixture of deuterated acetone with protic water and protic trifluoroacetic acid $(85: 10: 5, \mathrm{v} / \mathrm{v})$ was appropriate. It led to only partial exchange of the 5-H, which at the same time facilitated its assignment, and it also fulfilled another spectroscopic requirement. The presence of a considerable amount of protons from the solvent ( $) 10^{4}$ fold molar excess with respect to the Pfr peptide) leads to a very strong solvent line in the NMR spectrum. This can principally be coped with by using a computer with a sufficiently high dynamic range, but only if this line is well separated from the resonance lines of the solute. Since the chemical shift of water is strongly increased in the presence of acid, the amount of acid added to the system can be used to adjust the water line to a position where it does not interfere with the solute lines of interest.

With all the conditions adjusted accordingly, it was then possible to obtain the NMR spectrum of a Pfr chromopeptide 

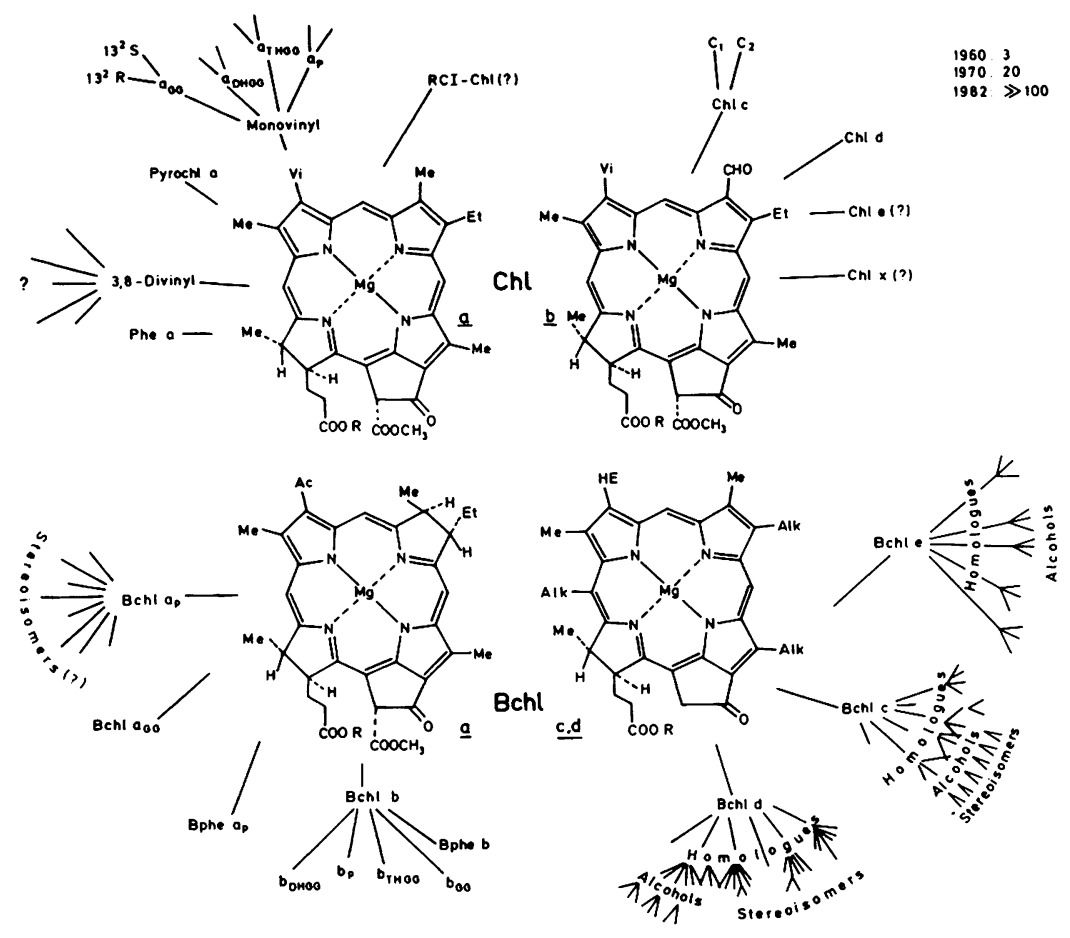

Fig.2: The "chlorophyll explocion". The time table in the upper right givea the number of reaconably well eatabliahed atructurea.

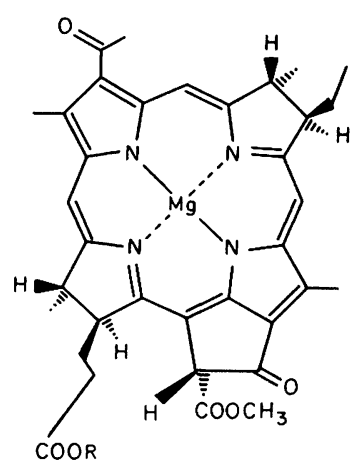

7: $R=$ phytyl 
at the first shot (7). Phytochrome accumulated over a period of several months was phototransformed to $\mathrm{Pfr}$, degraded and purified over night to the peptide by the biochemist, taken over by the NMR crew and rushed in the early morning hours to the $500 \mathrm{MHz}$ NMR spectrometer $300 \mathrm{~km}$ away in the laboratories of the BRUKER company. After measuring first the spectrum of the Pfr peptide, the latter was photochemically converted in the NMR tube to the $\underline{\mathrm{Pr}}$ peptide by irradiation with white light.

The analysis of the spectra clearly established the Pfr chromophore as the $5 \mathrm{Z}, 10 \mathrm{Z}, 15 \mathrm{E}-\mathrm{isomer} 1 \mathrm{~b}$ of the all-Z Pr chromophore 1a. This structure follows mainly from the analysis of the methine proton signals. Studies with the $\mathrm{Z}, \mathrm{E}-\mathrm{isomers}$ of $\mathrm{PC}$ and of the dihydrobilindiones $4 \mathrm{a}, \mathrm{b}$ (8) and $6 a, b, c$ (9) have shown, that the chemical shifts of the methine protons are somewhat solvent dependent. However, the incremental shifts upon $Z, E-i s o m e r i s a t i o n$ are solvent independent, and characteristic for the site of isomerisation (table 1). The largest incremental shift is always observed at the site of isomerisation. In the Pfr chromopeptide, the position of the methine signals of the chromophore agree reasonably well with those of the $5 \mathrm{Z}, 10 \mathrm{Z}, 15 \mathrm{E}-\mathrm{isomers} 2 \mathrm{~b}$ and $4 \mathrm{~b}$ ( $\mathrm{fig}$. 1). There is a second set of lines corresponding to the $\mathrm{Pr}$ chromophore, which is always present and continously formed in Pfr peptides and amounts to $\approx 50 \%$ in the actual sample. This second set of lines increases accordingly upon photoconversion at the expense of the first set, thus proving directly the relationship of the two species. The largest incremental shift is observed for the $15-\mathrm{H}$ signal, and the Pfr chromophore must then contain the $15 \mathrm{E}-\mathrm{isomer} 1 \mathrm{~b}$ rather than the 5E-isomer 1c (or the for other reasons unlikely 10 E-isomer) (7).

\section{B.b.: NEW CHLOROPHYLLS}

The number of chlorophylls has been rather limited until recently, when an "explosion" of new chlorophyllous pigments raised their number well beyond into account. It becomes still larger if all suggested or suspected structural variations are counted (fig. 2). A sound structure analysis of even the minor pigments seems not only urgent, but also possible with the recent advances in spectroscopy. It should help to separate the chlorophylls proper from metabolites and artifacts, and to provide a structural basis for their functional studies.

There are two general approaches for the structure elucidation of chlorophylls. The first is the direct 


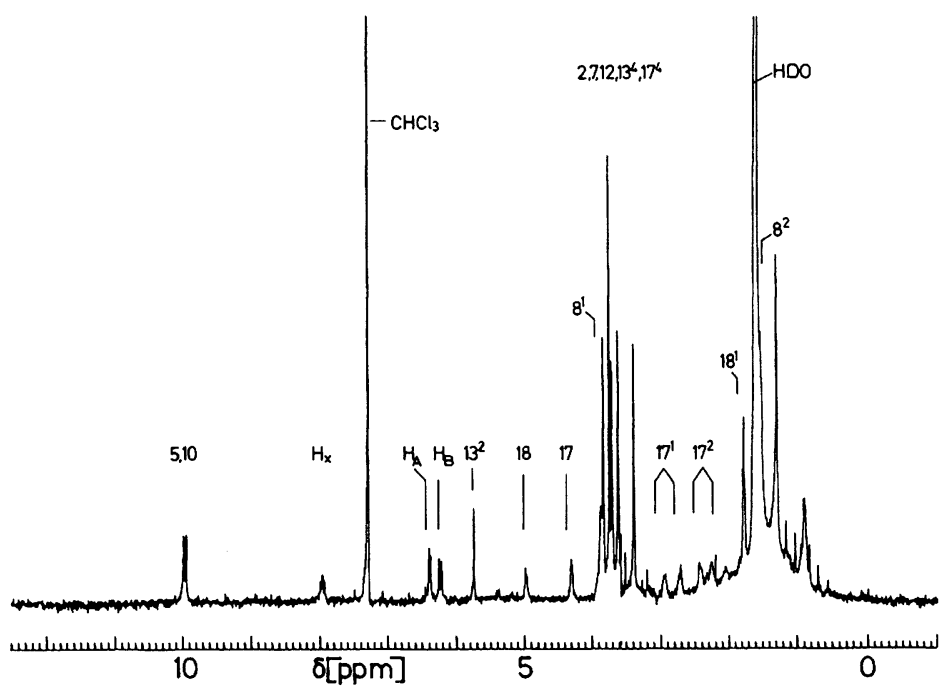

Fig. 3: ${ }^{1} \mathrm{H-NMR-apectrum} \mathrm{(500} \mathrm{MHz}$ ) of methylpheophorbide-RC I ( $40 \mu \mathrm{g}$ in $\left.\mathrm{CDCl}_{3}\right)$. The apectrum ia ratier cimilar to that of lephe a (3) at the came conceptrations, but the 15- $\overline{\mathrm{H}}$ is lacking and the $13^{2}-\mathrm{H}$ is ahifted to higher field. The apectrum is compatible with structure 11 for Meple-RC I.

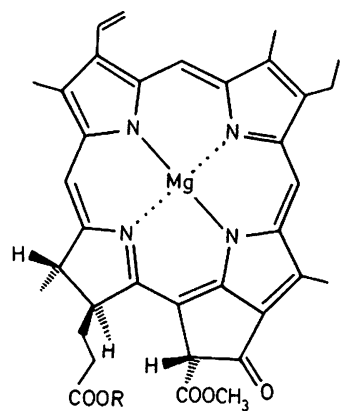

10

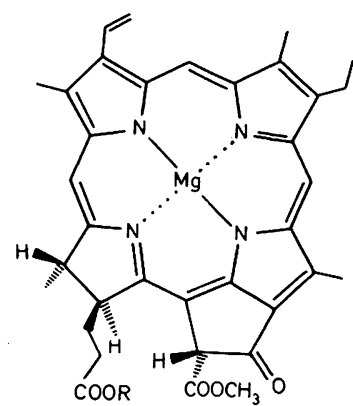

11 
analysis of the isolated pigments. It can be limited by the instability of the pigments, but is always necessary if the molecule cannot be modified without extensive and potentially unknown structural changes (see Bchl b as an example (10). The second is the controled conversion to derivatives like the methylpheophorbides which are more stable and thus amenable to a broader variety of analytical techniques, and which also provides already a means of chemical structure relations (see e.g. the identification of pyropheophetin as a degradation product (11) or of "divynil" Chl a as a biosynthetic precursor (12). NMR spectroscopy can usually be performed with both the genuine pigments and their derivatives. It gives a wealth of information and is interpreted in a straightforward fashion due to the inherent magnetic properties of the tetrapyrrole macrocyle (13). The latter serves as a builtin shift reagent which spreads the proton NMR spectrum over a range from $\delta=-6$ to $12 \mathrm{ppm}$. The only major source of error is the pronounced solvent and concentration dependence, which is related to the facile aggregation of these pigments. The second key method, mass spectroscopy, has been widely used for the demetalated pigments (14) but not been suitable for the chlorophylls proper, viz. magnesium complexes of pheophorbides. The latter cannot be analyzed by conventional mass spectroscopy with electron impact ionization. Several different ionization techniques have now been applied successfully to circumvent this problem. BRERETON et al. (15) have used the "in beam" ionization technique to determine the structure of the allomerization product $\mathcal{Z}$ of bacteriochlorophyll a (ㅇ) . KATZ and others $(15,16)$ applied field and $252 \mathrm{Cf}$ plasma desorption as well as fast atom bombardment to a variety of the "conventional" chlorophylls.

The latter mass spectroscopic technique has also been applied to one of the new chlorophylls, e.g. Chl-RCI (17). This pigment occurs only in trace amounts in organisms capable of oxygenic photosynthesis, where it has been quantitatively related to the contents of $\mathrm{P} 700$, the reaction center of photosystem I( PS I) (17). The latter is generally believed to contain the "normal" chlorophyll a (2) in a special environment and/or aggregation state (see section Cd). The suggestion that the red shift and other changed properties of $P 700$ may be due to a modified molecular structure (viz. Chl-RCI, is therefore of considerable interest.

Although the structure of $\mathrm{Chl}-\mathrm{RC} I$ is at present not yet fully elucidated, the known data are included here as an example for the general approach to new structures in the 
chlorophylls which are accessible only in small quantities. DOERNEMANN and SENGER (17), who first described and isolated the compound from a Scenedesmus mutant enriched in PS I, used the first aforementioned approach and studied the pigment proper. They obtained a satisfactory $252 \mathrm{Cf}$ plasma desorption mass spectrum, which gave a molecular ion which is 35 mass units higher than that of Chl a (9). They also obtained NMR evidence, that the $\overline{C-20}$ methine proton is missing. With a sample provided to us by the authors, we could show that the red-shift (as compared to the respective derivatives of 9) is maintained when Chl-RC I is demetalated to its pheophytin and transesterified to the methylpheophorbide, Mephe-RC I. The uv-vis-nir absorption of the latter is furthermore characteristic of a pigment similar to methypheophorbide $\underline{a}(10)$ but carrying a substituent other than a hydrogen atom at $\mathrm{C}-20$. This interpretation was also supported by the CD spectrum. It showed an increased ratio of the ellipticities of the red and the near-uv ("SORET) band, which is characteristic for steric hindrance due to substitution at methine position(s). The convertibility of CHl-RC I to its methylpheophorbide without an apparent $\overline{10 s}$ of the important structural variations was then used by us to obtain larger $(\approx 100 / \mathrm{ug})$ amounts of methylpheophorbideRC I from a different organism. The blue-green alga, Spirulina geitleri is available commercially as a spraydried powder (Behr, Bonn, FRG). The material is extracted exhaustively with methanol, and the crude extract containing mostly $\mathrm{Chl}$ a is immediately demetalated. The resulting pheophytin mixture is chromatographed on silica and transesterified to the methylpheophorbides. Further repeated chromatography of the latter on silica, and finally HPLC on a reverse phase adsorbent yielded the pure Mephe-RC I. The $500 \mathrm{MHz}$ proton NMR spectrum (fig.3) was again obtained at the BRUKER facilities. It fully supported the substitution of $\mathrm{C}-20$, and showed otherwise all signals present in Mephe a (10). Variations of the chemical shift can be accounted for by the low concentration of the former, with the possible exception of the rather large shift of the $132-\mathrm{H}$ signal. The "conventional" electron impact mass spectrum gives a molecular ion which is 50 mass units higher than that of 10 and shows an unusally intense $(M+2)$ ion, which may relate to the presence of $\mathrm{Cl}$. Taken together with chemical and chromatographic evidence not discussed here, these results are compatible (but not proof yet) of the 13 -oxy-20-chlorostructure 11 for Mephe-RC I. Recent field desorption data support this structure. 


\section{B. c.: BIOSYNTHESIS OF TETRAPYRROLS}

Radiactive labeling 1 the most sensitive method to study metabolic pathways, but it has several shortcomings which can be overcome by heavy labeling with stable isotops. The latter are detected by either mass or NMR spectroscopy. A particular advantage is the easy distinction of double labeling within a subset of molecules from a statistical distribution at two or more sites. BROWN et al. have used 170 labeling in conjunction with masspectroscopy to establish a twofold oxygenation with 0 during bile pigment formation from heme in red algae. Spin-spin coupling in NMR gives even a more detailed history on the biosynthetic pathway, as demonstrated elegantly for the sequence of reactions involved in the cyclisation of four porphobilingens to uroporphyrin fII (21a).

${ }^{1} \mathrm{C}$ labeling in conjunction with NMR has recently also been applied to plants, where it provided conclusive evidence for the predominance of the so-called $\mathrm{C}_{5}$-pathway for chlorophyll formation in maize $(21 \mathrm{~b}, \mathrm{c})$. The key intermediate $\delta$-aminolevulinate (Ala) is formed in this pathway from $\mathrm{C}_{5}$ compounds like glutamate ork etoglutarate, rather twan from ${ }^{5}$ succinate and glycine. With the ${ }^{3}$ C-NMR spectrum of chlorophyll a fully assigned, the lable in any of the 35 c-atoms ofthe macrocycle can be quantitated in a single experiment. The ł⿳亠chnique requires, however, a substantial incorporation of ${ }^{1} \mathrm{C}$ above the $1.1 \%$ level of natural abundance. Since the uptake of organic substrates by plants is low, and their metabolism more complex than that of animals, it may be incorporation can then be used to test the feasibility of the experiment. PORRA et al. incorporated after such tests 1500 excised primary leaves of maize seedlings with selectively labeled ${ }^{13} \mathrm{C}-\mathrm{glutamate}$. The contribution of the $\mathrm{C}$-pathway to the chlorophyll biosynthesis in maize is from these experiments $>95 \%$, and similar data are obtained for 3 beans by OHAMA et al. The only position labeled by $2-{ }^{3} \mathrm{C}$ glycine is $\mathrm{C}-13^{2}$, 技e methylester group at the isocyclic ring. Feeding with $1-{ }^{13} \mathrm{C}$ glutamate yieled a label in all $\mathrm{e}^{\mathrm{ight}}$ positions originating from C-5 of Ala, and feeding 5- ${ }^{3} \mathrm{C}-g l$ tytamate brings the lablel to the two ester group $\mathrm{C}-13^{4}$

Labeling in some other positions can furthermore be accounted for quantitatively by a partial conversion of $5-{ }^{13} \mathrm{C}$ to $1-{ }^{3}$-glutamate via the citric acid cycle. 


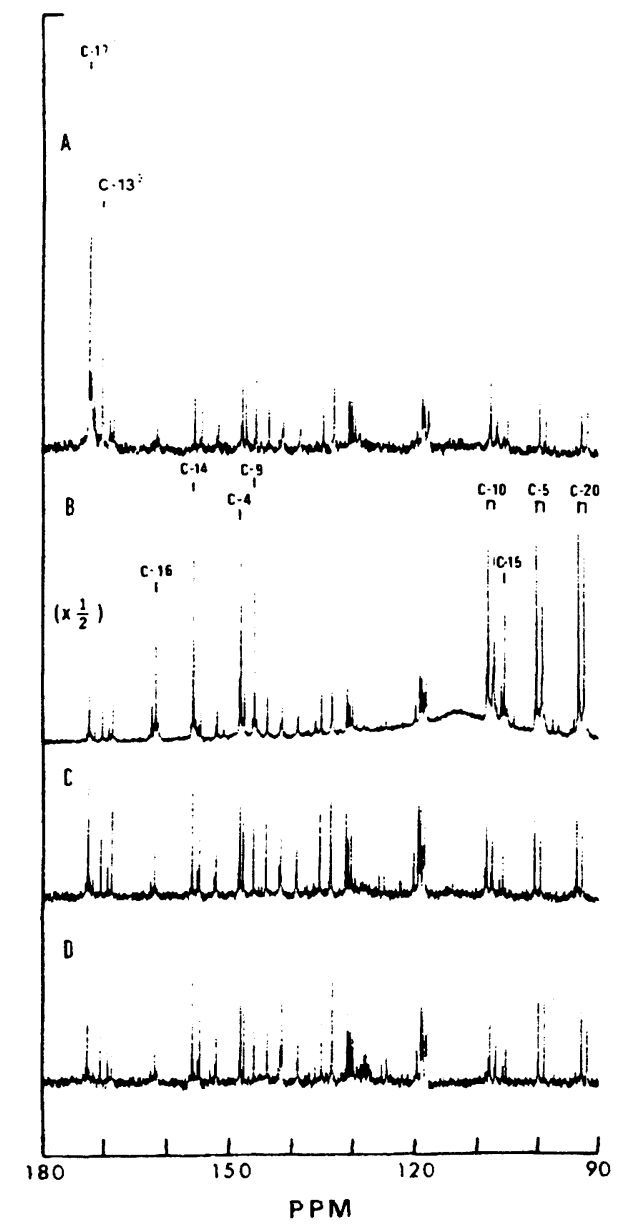

Fig. 3 A: Proton-coupled ${ }^{13}$ C-NMR spectra from $90 \mathrm{ppm}$ to $180 \mathrm{ppm}$ of chlorophyll a produced by illumination of excised etiolated maize leaves in the presence of $5-{ }^{13} \mathrm{C}$ glutamate (A). $1-13 \mathrm{C}$ glutamate (B) and $2-13 \mathrm{C}$ glycine (C). Spectrum $D$ is the natural-abundance ${ }^{13} \mathrm{C}-\mathrm{NMR}$ spectrum of chlorophyll a. The vertical axes of spectra $A$. C and $D$ are expanded twofold relative to that of spectrum B. From PORRA et al. (21b). 


\section{C: TETRAPYRROLES IN COMPLEX SYSTEMS}

The functions of tetrapyrroles can only partly be unterstood on the basis of their molecular structure. The properties of e.g. the biliproteins are quite different (absorption, fluorescence) from what might be expected from the structures of the chromophores. Also, a particular pigment e.g. Chl a serves of ten rather different functions (light harvesting, electron donor, electron acceptor) in different environments. These changes are brought about by chromophore-protein and chromophore-chromophore interactions. To unterstand the function of tetrapyroles, their structure has thus to be known in a more general sense which encompasses these interactions. These investigations are generally most effective by the combination of biochemical and spectroscopic techniques. The former allow a study of the photosynthetic apparatus by topological studies and the isolation of functional subunits. Spectroscopic techniques serve as a control to ensure that these subunits have retained their properties, and as a means for their structure analysis in the aforementioned general sense. Neither one of the two standard methods for the analysis of molecular structures is currently applicable to complex systems like tetrapyrrole-protein complexes, whole organelles or organisms, or just larger aggregates. Proton NMR can generally not cope with the line broadening caused by the comparably slow tumbling of these systems, and mass spectroscopy fails for the difficulties involved in the ionisation process. Furthermore are both methods principally difficult to apply to mixtures. The need for both selectivity and sensitivity favors applications of two- or more dimensional methods, of which only three shall be discussed here. The first is fluorescence spectroscopy, which permits among others the analysis of complex mixtures and of energy transfer. The second is RAMAN resonance spectroscopy (RR), which adds a second dimension to the conventional absorption spectroscopy, and which is furthermore accessible to rather precise computer modeling. The third of the selected methods is ENDOR and related magnetic double resonance techniques, which are selective for paramagnetic species, and also well suited for theoretical analysis.

\section{C. a: BIOSYNTHETIC STUDIES USING FLUORESCENCE SPECTROSCOPY}

Fluorescence is, within the limits of photostability of the investigated structures, a non-invasive technique and thus applicable to complex systems. By recording the excitation spectra for a number of excitation wavelengths (or vice versa), it is possible to obtain a minimum set of 


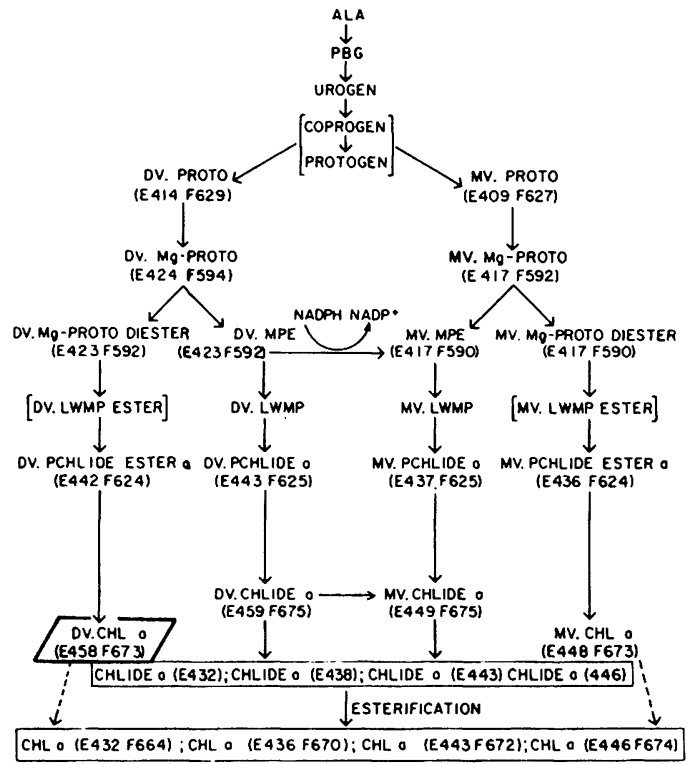

Fig. 4: Branched pathway for the biocyntheai of Chl a and homologuea, ac auggeated by REBEIZ et al. (ref.10). The clacaical pathway is the cecond one from the right. The atructure of divinyl-Chlorophyll a (12,boxed) has been confirmed by NMR, MS and $c \bar{h} \bar{e} m i c a l$ correlation $(12,22)$.

From REBEIZ (ref.20).

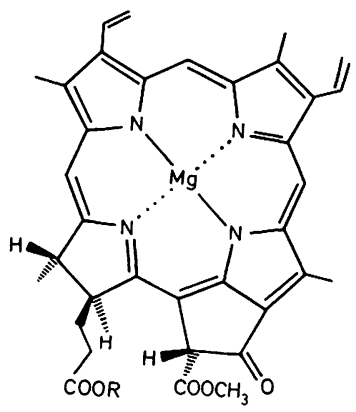

12: $R=$ phytyl 
components contributing to the fluorescence. The excitation spectra are furthermore similar to the absorption spectra of the individual components, if no energy transfer among the pigments (section C.b.) or other nonlinear effects take place. The two major limitations are the necessity of sufficient fluorescence, which has been improved e.g. by photon counting, but also the difficulty to establish a full structure from the absorption spectrum alone.

The metabolism of chlorophylls has long been known to involve a number of cyclic tetrapyrroles which are fluorecent (19). REBEIZ and coworkers (20) have exploited the fluorescence analysis of greening tissue to obtain more details on the biosynthetic pathway. In addition to the previously known chlorophylls and their metabolites they were able to characterize both in vivo and in extracts a variety of pigments with shifted absorption fluorescence spectra. From a careful comparison of the excitation spectra with the absorption spectra of known pigments, they suggested in particular a branched pathway leading to chlorophylls which carry not only the common vinyl group at $\mathrm{C}-3$, but have also still kept the second one at $\mathrm{C}-8$ all the way from protoporphyrin IX (fig. 4). The major argument for these structures was, that their excitation spectra showed like semisynthetic 3,8-divinyl-pigments, a considerably ( $\approx 10 \mathrm{~nm})$ red-shifted SORET-, but only minimally shifted $(2-3 \mathrm{~nm})$ long wavelength band. This proposed structural principle has now been proved for at least few of these pigments by the more informative methods described in section $B$. BAZZAZ et al. (21) have isolated 8-deethyl-8-vinyl-chlorophyli a (12) from a mutant accumulating large amounts of this pigment, and established its structure by NMR and mass spectroscopy, and REBEIZ et al. (22) have furthermore performed chemical correlations with this and other related pigments.

It is nonetheless desirable to increase the information content of the in situ fluorescence analysis, because the necessary reference material may not always be at hand. One such possibility is its extension in the form of fluorescence detected magnetic resonance (FDMR). WOLF et al., and others (23) have recently applied this technique to study. the pigments in photosynthetic bacteria. The biosynthetic pathway of bacteriochlorophyll a has been known in many details from studies with mutants (19). The conventional fluorescence analysis of hhodopseudomonas spheroides and other photosynthetic bacteria made now most of these pigments visible in whole cells, and indicated that some additional ones are present. In FDMR, the fluorescence at a selected pair of excitation/emission wavelengths is 

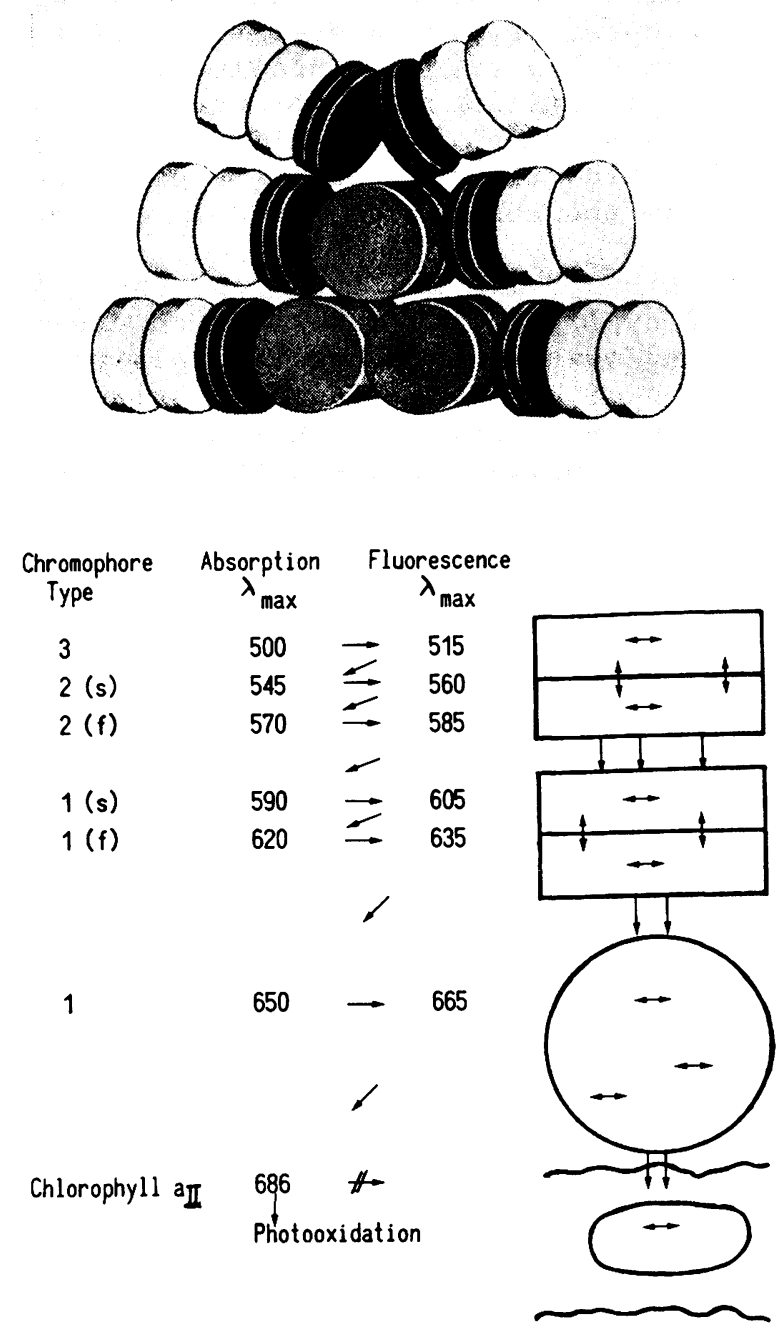

Fig.5: Models for the Rhodella violacea

Phycobilicome atructure (a, from refs.24c) and energy trancfer $\approx$ cheme (b, from refc.3). The outer "platea" ( $\lambda \max =500-570 \mathrm{~nm}, 1$ ight) in (a) contain B-PE, the intermediate onec (dark in (a), $\lambda \max =590-640 \mathrm{~nm}$ ) contain C-PC, and the inner core (gray in (a), $\lambda$ max $=650=$ $670 \mathrm{~nm})$ containa APC. 
monitored while a microwave field is swept, which gives the zero-field splitting parameters of the pigments in their triplet states. When applied to the bacteria, these parameters could be obtained for most of the pigments previously identified by fluorescence alone, and they agreed well with the expected values. The full potential of this technique is probably not yet exploited. First examples have demonstrated its use where unusual zero-field splittings can be expected. This does not only include chlorophylls complexes with unusual metals and biosynthetic precursors of the lesser investigated (bacterio)chlorophylls, but also perturbations due to the particular environment of a given pigment, viz. to the study of pigmentprotein and pigment-pigment interactions. (23 a, b d)

\section{C.b.: ENERGY TRANSFER STUDIES USING FLUORESCENCE SPECTROS- COPY}

Another important application of fluorescence spectroscopy has been the investigation of energy transfer processes. The majority of plant tetrapyrroles is involved in the light collection process of photosynthesis. They are bound to proteins and arranged in large light harvesting arrays. Light energy captured by one of the chromophores is efficiently transferred to neighboring ones and by repetition eventually migrates to the reaction center $(\mathrm{s})$, in which the conversion to redox energy takes place. Several such antenna systems have been studied,but probably none of them in such detail as the phycobilisomes. These are electron microscopically visible aggregates consisting mainly of biliproteins, which are attached to the outer surface of the photosynthetic membranes of blue-green and red algae. Their participation in the light harvesting process to photosystem II had been inferred from the classical biochromatic experiments of EMERSON and coworkers, and detailed studies became possible with the successful isolation of entire phycobilisomes and their more or less dissociated components (24). Phycobilisomes contain at least two, generally three chromoproteins bearing bile pigment chromophores. These are the green allophycocyanins (APC), the blue phycocyanins (PC) and -optionally- the red phycoerythrins ( $\underline{P E}$ ) (see fig. $\overline{5}$ for the spectral data).

All phycobiliproteins are highly fluorescent. Fluorescence studies of intact phycobilisomes had shown, however, that only the minor (generally $5 \%$ ) and red-most absorbing APC is responsible for the fluor escence, irrespective of $\mathrm{PE}$, PC or APC being the absorber. The energy is thus transported with high efficiency from the higher energetic (PC, $\underline{P E)}$ to the lower energetic component ( $\underline{\mathrm{APC}})$. This transfer 

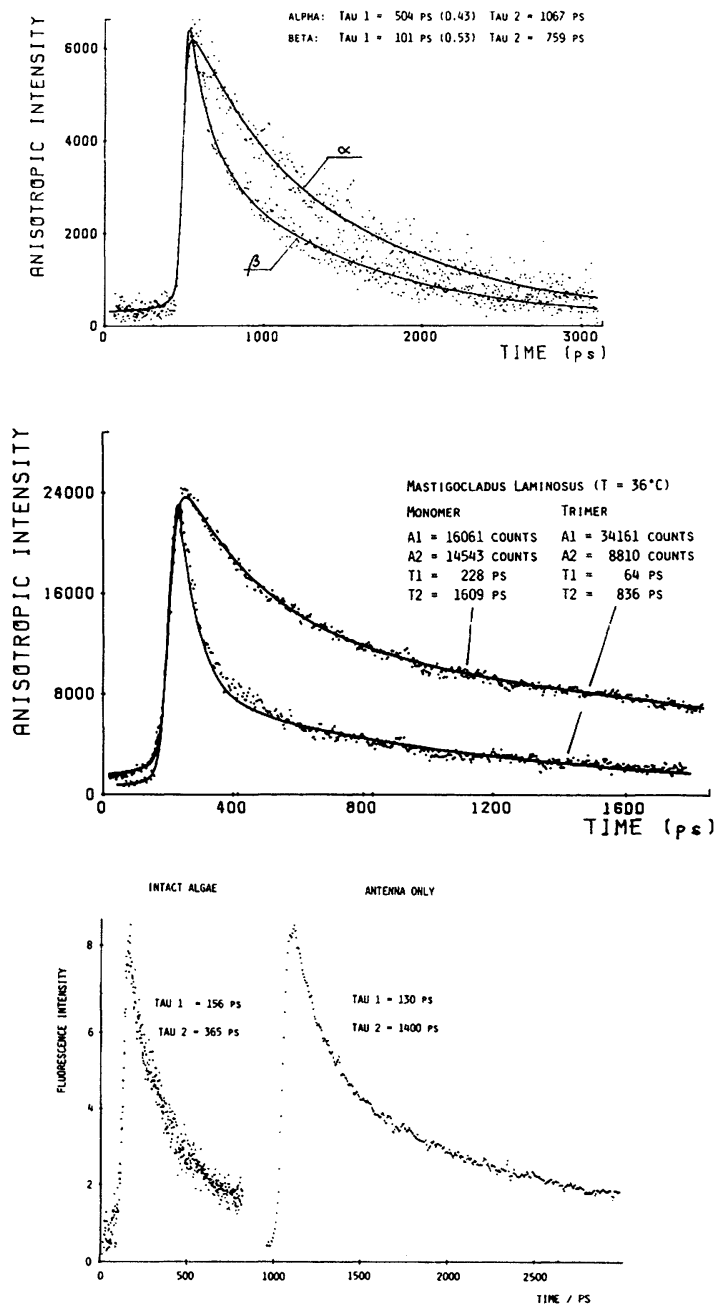

Fig.6: Fluoreacence decay curvec (pointa) and bect fit (Marquardt algorithm) for a biexponential decay (aolid linec). The maximum amplitudec and the time constanta are given in the inceta. (a) $\alpha$-and $\beta$-aubunit o of PC from Mactigocladuc laminocuc. (b) The came pigmenta in ite trimeric atate $\left(\alpha_{3}, \beta_{3}\right)$ and in ita monomeric state $\left(\alpha_{1}, \beta_{1}\right)$ induced ${ }^{3} b^{3}$ diecociation of the trimer with KsCN. (d) Phycobilisomec from Mactigocladua laminosus (right) and whole celle (left). Figa.(a) and (b) give only the anicotropic component of the fluoreccence, Excitatign at $580 \mathrm{~nm}$, pul a intenaity $10^{14}$ photone . $\mathrm{cm}^{-2}$, repetition rate $80 \mathrm{MHz}$. 
is uncoupled after the dissociation of the phycobilisomes, a process which can be monitored by the gradual increase of the fluorescence of the fragments. The biochemical and fluorescence analysis of the fragments yielded a model in which the morphology of the pigments as well as their absorptions and emissions are optimized for an efficient energy transfer (fig. 5). Most if not all of the chromophores are weakly coupled and the energy is transfered by a Förster type process, which is also supported by circular dichroism of the isolated pigments (25).

Whereas this static analysis is well suited to study the energy transfer between chromophores with well separated absorptions, the individual transfer steps between neighboring and more alike chromophores required more sophisticated methods. Fluorescence depolarization revealed a further subdivision of the chromophores (26). Even in pigments like $\underline{P C}$ and many of the $\mathrm{PE}^{\prime} \mathrm{s}$ bearing up to six chromophores of the same molecular structure, is the absorption (and fluorescence) of the individual chromophores fine-tuned for an efficient energy transfer. The three chromophores of C-PC absorb, for example, around 590,610 and $620 \mathrm{~nm}$, which allows a graded energy transfer even on this level. The static fluorescence experiments have been complemented by time-resolved studies. PORTER et al (27) monitored the small amount of leakage fluorescence emitted by $\mathrm{PE}, \mathrm{PC}$, and APC in intact algae. After excitation with green light absorbed mostly by $\mathrm{PE}$, the PE fluorescence rises first, followed by the fluorescence from PC and finally from APC. Excitation with laser pulses of varying photon fluence has also been used to study the migration of excitation energy via singletsinglet annihilation, which gives information on the number of coupled chromophores (28). It could e.g. be shown, that bacterial/antenna preparations with different detergents may have rather different numbers of coupled chromophores, in spite of their identical absorptions $(28 \mathrm{~b})$. These studies showed on the other hand, that rather low fluence rates are required to prevent interference from the latter process on the fluorescence decay rates obtained by picosecond time-resolved spectroscopy (see ref. 29 for a critical discussion).

Picosecond time-resolved spectroscopy has now been applied by several groups to investigate the energy transfer both in intact phycobilisomes and their componenents. $(41,43)$. The is rather complex. Each one of the applied methods of measurement and data handling has certain advantages and shortcomings, which are complicated by preparative problems. A consistent and detailed model can thus not yet be given and will require considerably more data. 
Table 2: Fluorescence decay (in psec) of phycocyanin from spirulina platenai.

\begin{tabular}{|c|c|c|c|c|c|}
\hline & & & & $\tau \quad$ Mo & er \\
\hline & $\mathrm{T}\left({ }^{\circ} \mathrm{C}\right)$ & $\tau_{2}(\%)$ & $\tau_{1}(\%)$ & $\tau_{2}(\%)$ & $(\%)$ \\
\hline $\begin{array}{c}0 \\
\text { U1 } \\
2 \\
0\end{array}$ & 18.6 & $1300(47)$ & $320(53)$ & $2200(51)$ & $300(49)$ \\
\hline$\stackrel{4}{+}$ & 39.2 & $1500(49)$ & $270(51)$ & $2200(54)$ & $290(46)$ \\
\hline ש. & 51.8 & $1600(36)$ & $260(64)$ & $3200(51)$ & $400(49)$ \\
\hline $\begin{array}{l}0 \\
-1 \\
0 \\
0 \\
0\end{array}$ & 18.6 & - & $70(100)$ & $1050(37)$ & $150(63)$ \\
\hline$\stackrel{4}{\dagger}$ & 39.2 & - & $70(100)$ & $1000(38)$ & $250(62)$ \\
\hline 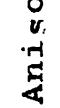 & 51.8 & $350(54)$ & $70(46)$ & $3500(47)$ & $380(53)$ \\
\hline
\end{tabular}

The inotropic decay curves are calculated from $I_{\|}+2 I_{1}$, the anisotropic ones from $I_{n}-I_{1}$. In a different set of experiments with C-PC from Mastigocladus laminosus, the calculated isotropic decay curve has been shown to agree satisfactorily with the experimental curve obtained with the emission polarizer adjuated to $55^{\circ}$. 
We have recently started a systematic investigation of isolated phycobiliproteins and their aggregates by timeresolved fluorescence depolarization. These studies use a repetitive streak camera for the detection, which allows for reduced photon fluence in the individual pulses. In a study with PC from two different algae, it could be shown that there is always a complex decay of fluorescence, which can be fit satisfactorily by a biexponential (fig. 6). The analysis of the components in the isotropic and anisotropic fluorescence yielded differest amplitues and rate constants, but the slow component was always less pronounced and in the aggregated pigments even absent in the polarized fluorescence (table 2). Since rotational depolarization can be excluded for proteins of this size on the picosecond time-scale, this depolarization has been assigned to energy transfer among the individual chromophores. It is accordingly more pronounced in the aggregates and appears to be absent in the $\alpha$-subunit bearing only a single chromophore (fig. 6a). The two rather long-lived components are here assigned to two species, the shorter lived being probably an artifact from the denaturation -renaturation necessary to separate the subunits. Additional support for the interpretation of the short lived component to reflect energy transfer comes from the increased difference between isotropic and anisotropic fluorescence with increasing aggregation (table 2). The decreased lifetimes in whole algae (fig. 6c) are finally understandable on the basis of a further transfer to the chlorophylls which acts as an efficient quencher for the biliprotein fluorescence. It should be pointed out, however, that a quantitative analysis of this process is at present rather difficult and depends not on the signal-to-noise ratio of the data, but also critical on the model. It was thus not possible to distinguish a biexponentialfrom a higher exponential or a more complex decay law (e.g. e- $\sqrt{t}$ ), which might be expected for a FOERSTER type energy transfer.

High-resolution spectroscopy in the time domain can also be supplementelby high-resolution spectroscopy in the frequency domain. Hole-burning experiments have been performed with chlorophylls and biliproteins (fig. 7) to yield highresolution absorbtion spectra (42). The process involves site-selective photochemistry at liquid helium temperatures, most likely protein transfer reactions, which leave a "hole" in the absorbtion band corresponding to the natural linewidth as determined by the kinetics of the process. In the case of C-phycoerythrin, these holes are acompanied by slightly wider satellite holes at the long-wavelenght side of the primary hole. They may be related to energy transfer between the different chromophores in this pigment (42a). 


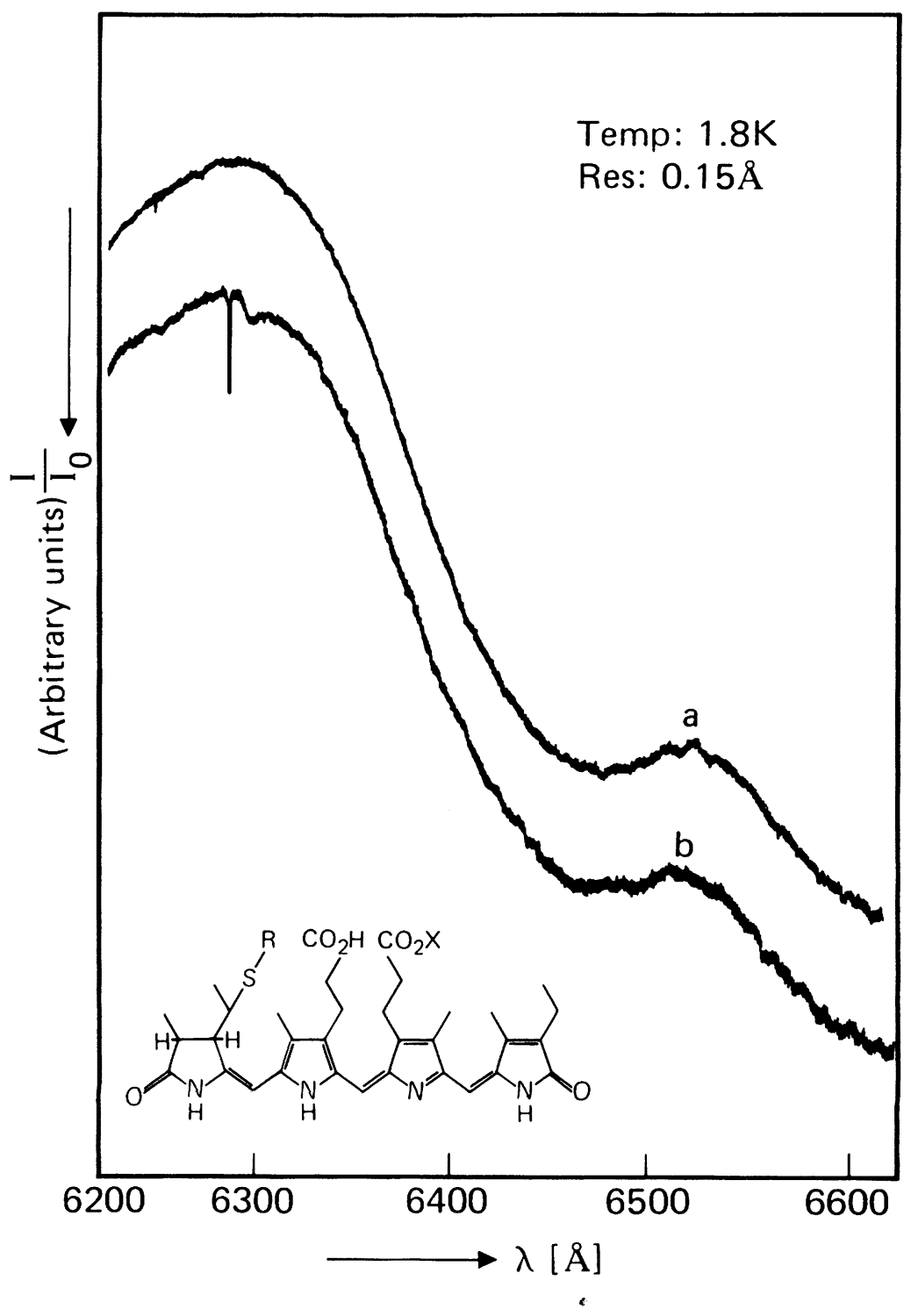

Fig.7: Hole burning experiment with a mixture of C-PC and APC from spirulina platensic after irradiation (b) with a narrow-band lacer. The aharp hole develope at the laser frequency. It ic accompanied by a broader phonon side-band. 


\section{C.C: NATIVE STATE OF CHROMOPHORES}

The properties of tetrapyrole chromophores are usually considerably changed when they are bound to the native apoproteins. Spectroscopy has become in many ways a mediator between the native structures and models mimicking certain aspects of this state. Chlorophyll aggegation has played an important role to evaluate its donoracceptor properties for coordinative bonding (44). Although the self-aggregation of chlorophylls appears currently less important in vivo, the interactions with the protein are governed by essentially the same factors. It is also well possible, that the forme: have been an older evolutionary feature which has later on been replaced by the latter, which may be suggested from the antenna system of green bacteria. In the biliproteins, conformational changes have been made most likely as an important factor determining the properties of the native state. The uv-vis spectral differences between native and denatured biliproteins, e.g. PC or $\mathrm{Pr}$, can be accounted for by an extended and cyclic conformation, respectively, of the chromophore (3). This has been supported both by the properties of synthetic bile pigments with restricted conformational freedom, and by M0 calculations. The comparable large red-shift of native $P$ can, however, not been rationalized on this basis alone. Fhere are only two experimentially studied processes leading to similarly large red-shifts, e.g. deprotonation and cation radial formation. Since the latter is unlikely from ESR data, the extended anionic 15-E structure $1 \mathrm{c}$ has been suggested for native $P$ $(1,3)$. More recently, we have obtained evidence that the hiff fluorescence of native biliproteins can be explained in terms of a restricted conformational freedom. This interpretation comes from the high fluorescence yield of rigid bilirubins, which we investigated in cooperation with A.R. Hol zwarth from Mülheim (Isr. J. Chem., in press).

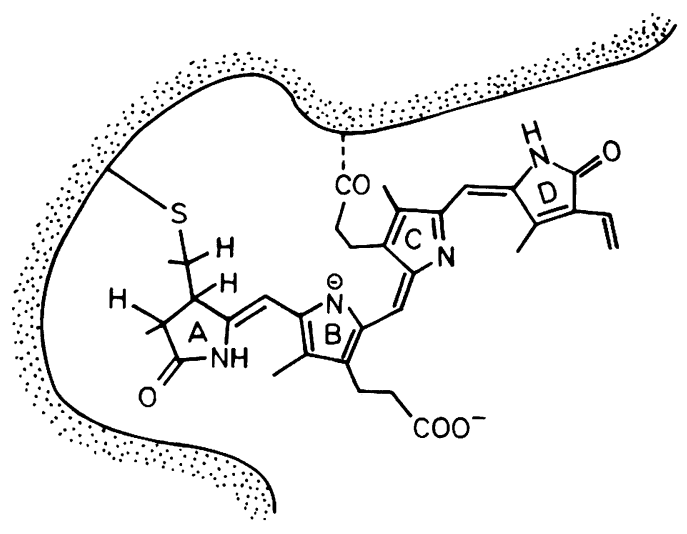



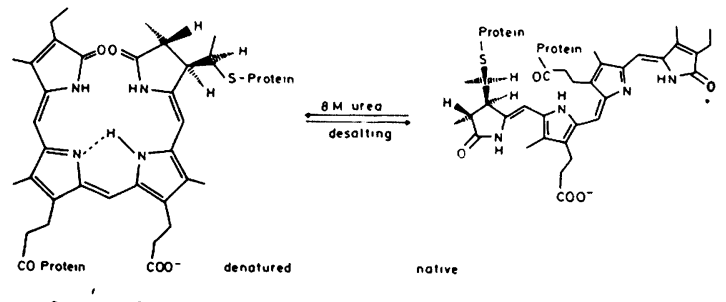

Structure 10a

native
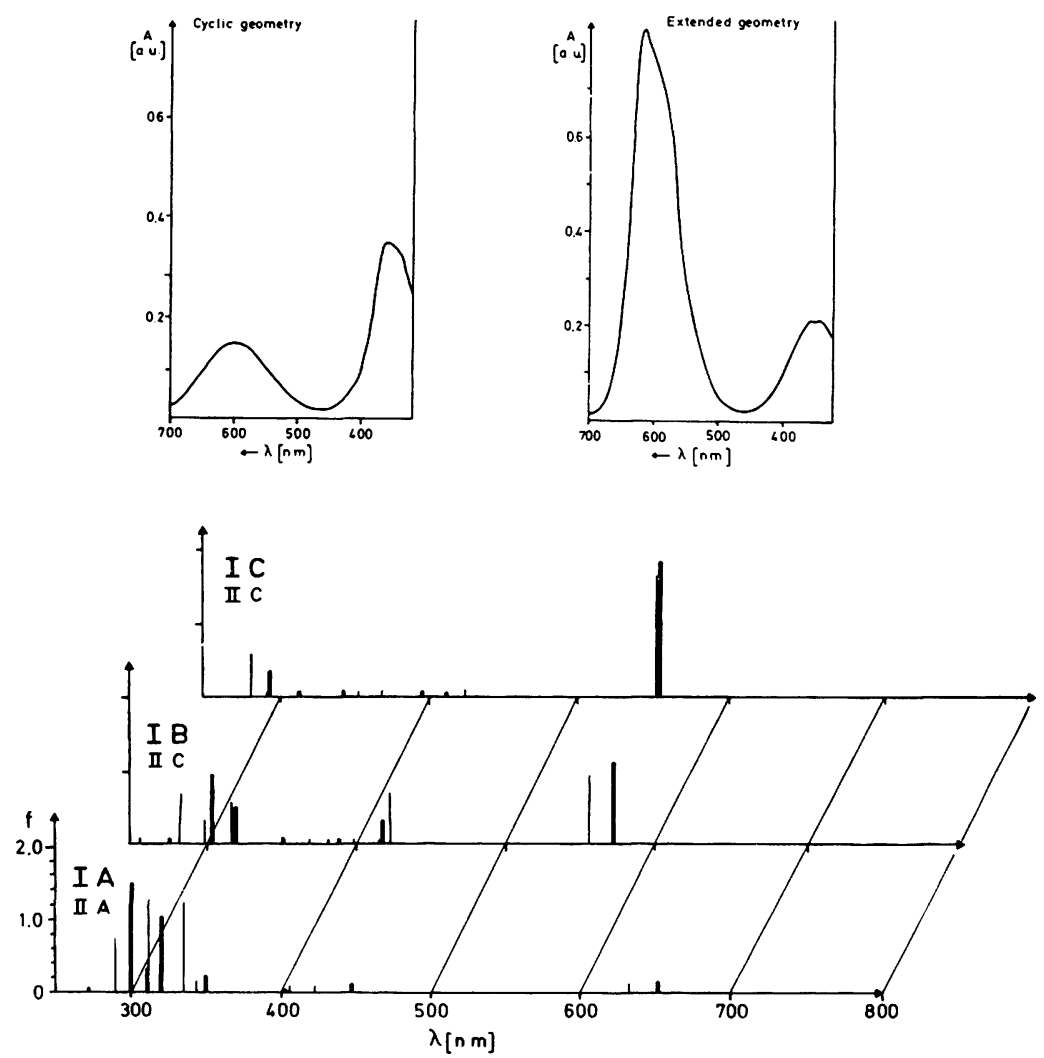

Fig. 8: suggeted geomety for the PC chromophore in ita native (right) and denatured atate, together with the correcponding experimental abeorption epectra (bottom of (a)) and the calculated opectra (I, II A,C, respectively). $I$ and II denote the tautomer, carrying a proton at $\mathrm{N}_{22}$ and $\mathrm{N}_{23}$, recpectively. $\mathrm{B}$ is the calculated opectrum for a cemi-open geometry. 
C.d: ENDOR SPECTROSCOPY OF THE PRIMARY DONOR IN PHOTOSYNTHESIS

Electron spin resonance (ESR) is a sensitive and highly selective technique for the investigation of paramagnetic species. It has also a comparably large information content and its theory is well worked out to allow the investigation of structures without too stringent requirements with regard to model compounds. The two major groups of paramagnetic structures in biological systems are heavy metal ions and organic radicals. Both participate among other functions - in biological oxidations and reductions, and important information has been obtained on these systems by the application of ESR. Major limitations are the overlap of signals from organic radicals, which are usually rlustered within a small spectral range and the limited time resolution, which has only recently been extended to the sub-nanosecond time scale.

One of the first studies of ESR in biology showed, that an unstructured line can be observed in photosynthetic tissue upon illumination. This signal (fig.9a) has later been assigned to the cation radical of the primary donor of bacterial reaction centers, or of photosystemI of green plants (29). The primary step during the photosynthetic energy conversion is the electron transfer from an electronically excited chlorophyll molecule to an acceptor which is probably also a chlorophyll or pheophytin. This leaves the primary donor as a cation radical, which is re-reduced on the $\mu \mathrm{sec}$ or msec time scale. Since the latter process is in most reaction centers rate limiting in strong light, the primary donor can be fully converted to the oxidized form during saturating irradiation. This results in the reversible, light induced formation of a strong ESR signal, and in the concomitant bleaching of absorption bands associated with the primary donor chlorophyll.

The optical changes are usually monitored around 700,870 and $960 \mathrm{~nm}$ in the reaction centers of PS $I, \underline{\mathrm{Bchl}}$ a and $\underline{B c h l}$ b containing bacteria, respectively. They are rather small, however, in all but highly enriched reaction center fractions, because they overlap with the absorption of antenna pigments present in large excess. Since the latter are ESR inactive, the ESR signal does not suffer from this interference. After the kinetic correlation of the two signals and its assignment to a chlorophyll cation radical, has ESR therefore been used extensively to monitor and to obtain structural information on the primary donor. The most data have currently been accumulated on bacterial systems, because the chemical identity of its origin is 

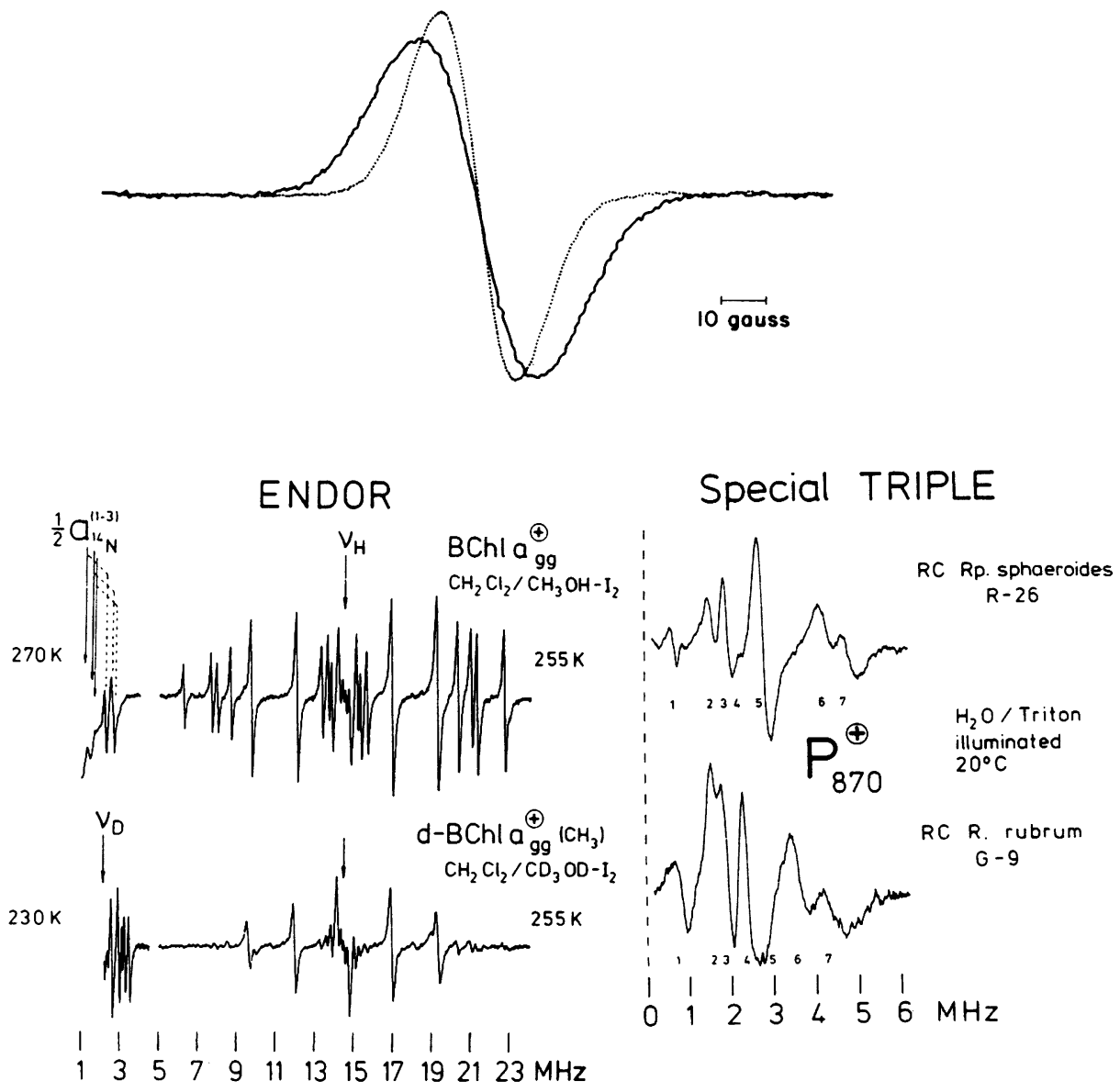

Fig.9: (a) ESR spectrum of the cation radical Bchl $a^{+}$in methanol $/ \mathrm{CH}_{2} \mathrm{Cl}_{2}$ (heavy line) and of $P 370^{+}$in icolated reaction centere from Rhodopaeudomona opheroides (thin line). (b) ENDOR spectrum of fully protonated (upper trace) and celectively deuterated $B c h 1 a^{+}$in the came colvent cyatem. (c) special TRIPLE spectrum of $\mathrm{P} 870^{+}$in reaction centere from Rhodopeeudomonae epheroides R26 (upper trace) and Rhodoapirillum rubrum G9. In thic technique, two radiofrequenciea are applied cimultaneoualy which are eymmetric to the free proton frequency $\left(=\boldsymbol{r}_{\mathrm{H}}\right.$ in $\left.b\right)$. 
well established ( $\underline{B c h l} \underline{a}$ or $\underline{B c h l} \underline{b}$ depending on the species), and reaction centers can be isolated which are essentially free from other components of the photosynthetic apparatus $(30)$.

The ESR spectra of chemically oxidized bacteriochlorophyll a in solution and of the light induced in situ signal of the primary donor in Bchl a containing bacteria are very similar (fig.9a). Thonly exception is the line width, which is reduced in the natural systems by a factor of 1.4. NORRIS and coworkers were the first to relate this narrowing to aggregation, and arrived at an aggregation constant of two from a second moment analysis ("special pair" model) (31). This interpretation was later on supported by electron-nuclear double-resonance (ENDOR) spectroscopy. This allowed the resolution of at least five coupling constants in the inhomogeneously broadened ESR line. All resolved ENDOR couplings were reduced in the in situ signal by a factor of about two as compared to the signal of free Bchl b, which strongly supported the above model (32).

A drawback of earlier ENDOR studies had been their restriction to low temperatures ( $\leqslant 77 \mathrm{~K})$. The development of ENDOR at ambient temperatures by MOEBIUS and coworkers prompted us a few years ago, to study in cooperation with them bacterial reaction centers in liquid solution (33). This is not only an advantage with respect to the more physiological temperatures, but gives also a considerably increased resolution due to the averaging of dipolar interactions (fig. 9). The ENDOR lines were assigned by a combination of isotope labeling, chemical correlations and spectroscopic techniques (fig. $9, \mathrm{~b}, \mathrm{c}$ ) and the results are summarized in table 3 . for reaction centers from two photosynthetic bacteria, Rhodopseudomonas spheroides and Rhodospirillum rubrum. There are some distinct and preparation independent differences between the species (fig. 9) but the general picture is identical: All coupling constants in the reaction centers are reduced in comparison to the respective couplings from oxidized Bchl a in solution. The reduction factors are, however, considerably different for different proton couplings, which indicates a redistribution of the spin densities in the oxidized primary donor. The average reduction factor is, however, again close to two, thus indicating again a dimeric structure for P870.: There is furthermore only one set of lines for each coupling in the in situ species, e.g. the individual lines are not split. Since such a doubling of lines would be expected for an unsymmetric spin distribution over the two halves of the special pair, this argues 
Table 3: Comparison of isotropic hfc's a (MHz) of $\mathrm{Bchl} \underline{\underline{a}}^{+}(255 \mathrm{~K})$ and $\left.\mathrm{P}_{870}+0^{\circ} \mathrm{C}\right)$ cation radical.

\begin{tabular}{|c|c|c|c|c|c|}
\hline \multirow[b]{2}{*}{ position } & \multirow[b]{2}{*}{$\mathrm{a}^{\mathrm{Bch} 1} \mathrm{a}_{\mathrm{gg}, \mathrm{P}}^{+}$} & \multicolumn{2}{|c|}{$R-26$} & \multicolumn{2}{|c|}{$G-9$} \\
\hline & & $\begin{array}{c}\mathrm{P}_{870}^{+} \\
\mathrm{a}\end{array}$ & RF & $\begin{array}{l}\mathbf{P}_{870}^{+} \\
\mathbf{a}\end{array}$ & RF \\
\hline $\mathrm{CH}_{3}$ (1a) & +4.85 & +4.00 & 1.21 & +3.40 & 1.43 \\
\hline $\mathrm{CH}_{3}(5 \mathrm{a})$ & +9.50 & +5.60 & 1.70 & +4.85 & 1.96 \\
\hline$B-H$ & +11.61 & $+3 \cdot 30$ & 3.52 & +3.95 & 2.94 \\
\hline$B-H$ & +13.00 & +4.45 & 2.92 & +5.28 & 2.46 \\
\hline$B-H$ & $+13 \cdot 59$ & +8.60 & $1 \cdot 58$ & $+7 \cdot 50$ & 1.81 \\
\hline$B-H$ & +16.43 & +9.50 & 1.73 & +8.50 & 1.93 \\
\hline
\end{tabular}
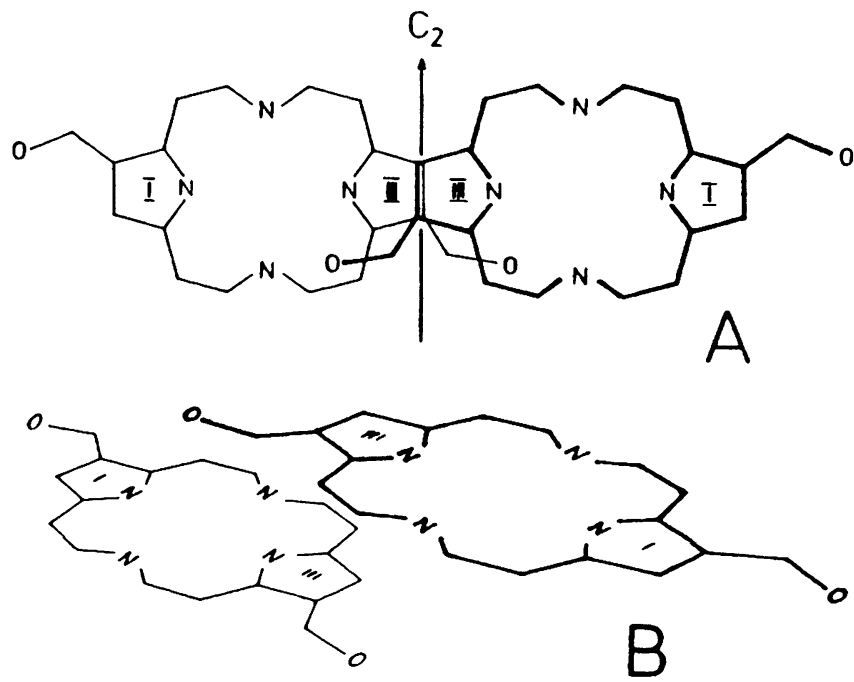

Fig. 10: Proposed geometry for $\mathbf{P}_{870} t$, the oxidized primary donor of bacterial (Bchl a)photosynthesis. The plane-to-plane distance of the molecules is 3.5-4A. The fit is obtained from simulations of the ESR line shown in fig. 9 with the couplings from table 3 . 
for a dimer with C2 symmetry.

The experimental spin densities can now be used to simulate the ESR spectrum. A satisfactory fit is again only obtained under the assumption of a dimeric species for the oxidized primary donor. Based on these data has the Berlin group recently started molecular orbital calculations to assess the geometric relationship of the two molecules in the special pair. The two Bchl a molecules are treated as a super-molecule in these calculations. The preliminary results make the model shown in fig.10 most likely. The two molecules have a $C 2$ axis, and they are essentially parallel $\left(\leqslant 5^{\circ}\right)$ to each other at a distance of 3.5 to $4 \mathrm{~A}$. The two macrocyles are, however, shifted against each other and overlep only in the region of ring three. This model fits all the data, it accounts in particular for the symmetry of the entire system, and also for the observed spin density redistributionin the two halves.

Whereas it is rather nicely self-consistent, some constraints should be pointed out. It is firstly only applicable to Bchl a containing reaction centers from the Rhodospirillales, and the available ENDOR data indicate a rather different situation for Bchl b containing reaction centers and for the photosystem $I$ and $\bar{I}$ of oxygenic photosynthesis. This is also evident from recent ESR experiments with organisms highly enriched in both ${ }^{13} \mathrm{C}$ and $2 \mathrm{H}$, which rather support a monomeric structure for the latter (35), and from the recent indication that a pigment structually different from $\mathrm{Chl}$ a is present in photosystem I (section B.b). There is finally a suggestion that severe distortions of the highest occupied molecular orbital (by mixing in of the energetically close lowest unoccupied MO), could principally explain the experimental data also with a monomeric species (36). Although none of our data give indications that this suggestion is correct, the model predicts some characteristic features (high spin density at the central nitrogen and methine positions) which are at least principally accessible to conclusive and direct measurements (e.g. ${ }^{15} \mathrm{~N}-1$ abeling). Such tests are currently ander way. 
C.e.: RAMAN RESONANCE STUDIES IN PHOTOSYNTHESIS

$\underline{\text { RAMAN }}$ resonance ( $\underline{\mathrm{RR}})$ is probably one of the most general techniques for the study of complex pigment systems, because it is very sensitive, widely applicable, quite selective, provides an extremely high time resolution and is accessible to a rather straightforward theoretical analysis. The technique makes use of the strong enhancement of the RAMAN spectrum of pigments, if the excitation occurs in one of its absorption bands. This reduces the background from ubiquitous components like proteins on water sufficiently for a selective study. The major problem besides technology - is the interference of even low levels of fluorescence. Unfortunately are most photosynthetic pigments highly fluorescent, but this problem can be circumvented by excitation into higher excited states, e.g. into the SORET band. Another problem is then, however, the overlap of the absorption lines of many pigments in this spectral range, which can partly be circumvented by appropriate biochemical manipulations (isolation of complexes, redox changes) and by spectroscopic means (variation of the excitation wavelength). Two laboratories have concentrated in the past few years on $\underline{R R}$ spectroscopy of photosynthetic pigments, in particular the chlorophylls $(37,38)$. COTTON et al. (38) have begun with a systematic study of in vitro systems, e.g. free chlorophylls in different states of aggregation and oxidation, to obtain an interpretational basis for photosynthetic camplexes. LUTZ et al. (37) have started with biological systems (whole cells, chlorophyll-protein complexes), and based their interpretation strongly on such complexes for which good structural data are available (e.g. the water-soluble antenna bacteriochlorophyllprotein from Prostecochlorus aestuarii).

There are two spectral regions in the $\mathrm{RR}$ spectra of chlorophyll (-protein) which are well accessible to analysis. One is the carbonyl region, which shows the $\mathrm{C}=0$ groups which are conjugated to the macrocycle $\pi$-system. Their binding state and conformation can be assesed from shifts and intensity variations, respectively, in the carbonyl stretching $b$ ands. The major conclusion from these data was, that a differentiation is possible among most of the individual carbonyl groups to be expected from the number of chlorophylls present in a particular chromoprotein, and that most if not all carbonyl groups are hydrogen bonded, probably to the apoprotejn. The second most informative region is around $300 \mathrm{~cm}^{-1}$, which has been assigned to the central $\mathrm{Mg}-\mathrm{N}$ vibrations. There is again one general result, e.g. the central $\mathrm{Mg}$ is five coordinated in most of the pro- 
tein bound pigments.

Studies with bacterial reaction centers showed changes in the carbonyl region upon oxidation of the primary donor, but few changes in other regions. LUTZ has used this as an argument against any close association among pigments, and in particular against the special pair model, because more pronounced changes are expected in aggregated systems (37a). The full meaning of this discrepan'cy is currently not yet clear. ENDOR and RR work at rather different time scales, which means that a hopping rate in the region of $1012 \mathrm{sec}^{-1}$ would be seen as a delocalized electron by the former, but a localized one by the latter technique. BOWMAN and (39) NORRIS have recently narrowed this time gap by spin-echo experiments, but it is still in the range of two orders of magnitude.

It is also desirable, that the $\mathrm{RR}$ method becomes more selective for the different pigments present in reaction centers, since only one or two of the six tetrapyrroles are part of the primary donor. Two promising extensions of the conventional technique have recently been applied for the first time to chlorophyll proteins, which may be useful in this respect. One is the surface enhanced RR, the complexes are deposited on a silver electrode. COTTON et al. (38a) have shown with bacterial reaction centers, that this enhances strongly the sensitivity and quenches the interfering fluorescence, and that it is also possible to enhance selectively the RR signal from different pigments within the reaction center by variation of the potential applied to the electrode. Another technique which is at least principally related to $\mathrm{RR}$ is the coherent antiSTOKES RAMAN scattering. Its most important advantage over conventional $R R$ is its greatly reduced sensitivity to fluorescence, because the vibrational lines are observed at the high-rather than the low-frequency side of the excitation line. HOXTERMANN et al. (40) have demonstrated, that this permits the measurement of chlorophylls in the red spectral region, which is much more sensitive to variations in the chlorophyll environment and thus allows more selective studies. Although the method seems to be somewhat less sensitive in the carbonyl region, it allowed like the RR technique a distinction of several bands assigned to the carbonyl groups of $\mathrm{Chl}$ a and $\mathrm{Chl} b$ molecules differing by their different environments. This sitespecific distinction is supported by the analysis of the more intense spectral region between 1600 and $100 \mathrm{~cm}^{-1}$. It is dominated by the double bond stretching vibrations of the the conjugated system, which also yield multiple lines in the chlorophyll proteins. The decreased interference of 
fluorescence in CARS renders its application to other pigmente poccible, e.g. the biliproteina. There is only a limited amount of RR data on their chromophores ( 40 , and CARs may help to get more details about their native chromophores.

\section{Conclusions}

It has been tried to sketch some recent examples of spectroscopic techniques to investigate plant tetrapyrroles, either isolated or in their more or less intact natural environment. It should be emphasized that all the selected examples required the cooperation of spectroscopists and biochemists although the latter havebeen neglected in this talk. None can do without the other in such research, which poses some problems in timing, a multiplied chance of breakdowns, and last not least sample transfer. The examples show, that these shortcomings are sometimes compensated by the results, which have led to an improved picture of the structure and function of tetrapyroles on the molecular level.

\section{References}

1. a) Rüdiger, W. 1980, struct.Bond. 40, pp. 101,

b) Rüiger, W. and Scheer, II. 1983, Encyclopedia of Plant Phy iology, 16, in preas

2. Klein, G., Grombein s. and Rüdiger, W. 1977, Hoppe-Seyler' Z.Phyciol.Chem. 358, pp. 1077-1079

3. Scheer, H. 1981, Angew.Chem. 93, pp. 230-250 and Angew. Chm. Int.Ed. 20, pp. 241-261

4. a) Gosauer, A., Hinze, R.P. and Kut ochan, R. 1981 Chem.Ber. 114, pp. 132-146, b) Placha-Puller, M. 1979, Dissertation Techn. Univeraität Brauncchweig

5. Rüdiger, W., Brandlmeier, T., Bloa, I., Gocaauer, A. and Weller, J.P. 1980, Z.Naturforech. 35c, pp. 763-769

6. a) Lagarias, J.C. and Rapoport, H. 1980, J.Am. Chem.Soc. 102, pp.4821-4828, b) Lagarias, J.C., Glazer, A.N. and Rapoport, H. 1979, J.Am.Chem.Soc. 101 , pp. 5030

7. Rüdiger, W., Thünmler, F., Ciniel, E. and Schneider, S., Proc.Natl.Acad.Sci. USA in presc

3. Kufer, W., Cmiel, E., Thümmler, F., Rüdiger, W., Schneider, S. and Scheer, H. 1982, Photochem. Photobiol. 36, pp. 603-607

9. Falk, H., Kapl, G. and Fuller, N., Monateh. Chem. in press

10.a) Scheer, H., Svec, W.A., Cope, B.T., Studier, M.H., Scott, R.G. and Katz, J.J. 1974, J.Am.Chem. Soc. 96, pp. 3714, b) Steiner, R., Cmiel, E. and 
Scheer, H., Z.Naturforsch. in preac

11. Schoch, S., Scheer, H., Schiff, J.A., Rüiger, W. and Siegelman, H.W. 1981, Z.Naturforech. 36c, pp. $827-833$

12. Bazzaz, M.B., Bradley, C.V. and Brereton, R.G. 1982, Tetrahedron Lett. 23, pp. 1211-1214

13. Scheer, H. and Katz, J.J. 1975 in K.M.Smith (ed.) "Porphyrine and Metalloporphyrinc" 2nd ed. Elcevier, NewYork.

14. H. Budzikiewicz 1978 in D.Dolphin (ed.) "The Porphyrins",V.III, chapter 9, Academic Presa, NewYork;

15. Brereton, R.G., Rajanada, V., Blake, T.J., Sandere, J.K.M. and Williams, D.H. 1980, Tetrahedron Lett. 21, pp. 1671-74

16. a) Conctantin, E., Nakatani, Y, Teller, G., Hueber, R. and Ourisson, G. 1981, Bull.soc.Chim. France, pp. 303-305, b) Hunt, J.E., MacFarlane, R.D., Katz, J.J. and Dougherty, R.C. 1981, J.Am. Chem.Soc. 103, pp. 6775-6778

17. Dörnemann, D. and Senger, H. 1982, Photochem. Photobiol. 35, pp. 821-826

18. Wolf, H. and Scheer, H 1973, Ann.N.Y.Acad.Sci. 206 , pp. 549

19. Jone, O.T.G. in Dolphin (ed.) 1978 "The Porphyrins" VI, chapter 3, Academic Press, NewYork

20. a) Rebeiz, C.A., Belanger, F.C., Freyssinet, G. and Saab, D.S. 1980, Biochim.Biophys.Acta 590, pp. 234-247, b) Rebeiz, C.A., Daniell, H., and Mattheis, J.R., Proceedings of the IVth symposium on biotechnology in energy production and convercation, in press

21. a) Batteraby, A.R. and McDonald, E. 1979, Acc. Chem. Rea. 12, pp. 14, b) Porra, R.J., Klein, 0. and Wright, P.E., Eur.J.Biochem, 130,pp.509-516 c) Ohhama, T., seto, H, Otake, N. and Miyachi, S. 1982, Biochen.Biophy..Re..Comm.105,pp.647-652

22. Belanger, F.C. and Rebeiz, C.A. 1982, J.Biol.Chem. 257 , pp. 1360-1371

23. a) Beck, J., v. Schütz, J.U. and Wolf, H.C. 1983 Z.Naturfor ch. 38, pp. 220-229, b) Beck, J., v. Schüt, J.U. and Wolf, H.C., Chem. Phy . Lett. in presa, c) Beck, J., v.Schüt, J.U. and Wolf, H.C., Chem.Phy. Lett., in precs, d) Searle,G.F.W., Koehor.t, R.B., Schaaf ma, T.J., Moller, B.L., and v.Wett.tein, D. 1981, Carlaberg Re-46 pp.183194

24. a) Gantt, E. 1981, Ann.Rev.Plant Phyciol. 32, pp. 327-347, b) Glazer, A.N. 1980 in D. Sigman, M.A.B. Brazier (eds.) "The Evolution of Protein structure 
and Function", Academic Press, NewYork, pp.221244 , c) Mörcchel, E., Koller, K. and Wehrmeyer, W. 1380, Arch.Hicrobiol. 125, pp.43-51

25. Holzwarth, A.R., Wendler, J., and Wehrmeyer, W. Biochim. Biophya.Acta in preas

26. a) Grabowaki, J. and Gantt, E. 1978, Photochem. Photobiol. 28, pp. 39-45, b) Teale, F.W.J. and Dale, R.E. 1970, Biochem.J. 116, pp. 161-169, c) Zickendraht-Wendelstadt, B., Friedrich, J. and Rüdiger, W. 1980, Photochem. Fhotobiol. 31, pp. $367-376$

27. a) Searle, G.F., Barber, J., Porter, G. and Tredwel1, C.J. 1978, Biochim.Biophy .Acta 501, pp. 246, b) J. Breton and Geacirtov, N.E. 1980, Biochim.Biophys.Acta, 594, pp. 1-32

28. Doukas, A.G., stefancic, V., Buchert, J. and Alfano, R.R. 1981, Photochem. P. 34, pp. 505-510

29. Hoff, A.J. 1982, Biophy.str. 8, pp. 107-150

30. Feher, G. and Okamura, M.Y. 1978 in R.K.Clayton and W.R.Si trom(eds.) "The Photocynthetic Bacteria," Chapter 19, Plenum Press, NewYork

31. Norris, J.R., Uphaus, R.A., Crespi, H.L. and Katz, J.J. 1971, Proc.Natl.Acad.Sci 68, pp.625

32. a) Wasielewaki 1982 in F.K. Fong (ed.) "Light Reaction Path of Photosynthesis, Chapter 7, Springer-Verlag, Heidelberg, b) Katz, J.J., Shipman, L.L., Cotton, T.M. and Janoon T.R. 1978, in D. Dolphin (ed) "The Porphyrins", V Chapter 9, Academic Press, NewYork

33. Möbius, K., Plato, M. and Lubitz, W. 1982 , Physica Report 87, pp. 171-208

34. a) Lendzian, F., Lubitz, W., scheer, H., Bubenzer, C. and Möbius, K. 1981, J.Am.Chem.Soc. 103, pp. 4635-4637, b) Lubitz, W., Lendziani, F., Scheer, H., Gottotein, J.., Plato, M. and Möbiue, K., Proc.Natl.Acad.Sci. in pres

35. Wacielewski, M.R., Norric, J.R., Crespi, H.L. and Harper 1981, J.Am.Chem.Soc.103, pp. 7664-7665

36. O'Malley, P.J. and Babcock, G.T., Proc.Natl. Acad.Sci., ubmitted for publication

37. a) Lutz, M. Brown, J.S. and Rémy, R. 1979 in "Chlorophyll Organisation and Energy Tranafer in Photosynthesis" (Ciba Foundation symp.61 ed. G. Wolatenholme, D.W.Fitzeimmons), Excerpta liedica, Amaterdam, pp. 105-125, b) Lutz, M. 1981 in "Photosynthesis" III (ed. G.Akoyonoglu), Balaban, Philadelphia, pp. 461-476

38. a) Cotton, T.M. and Vanduyne, R.P. 1981, J.Am. Chem.Soc. 103, pp. 6020-6026, b) Cotton T.M. and Vanduyne, R.P. 1982, Feb.Lett. 147, pp. 81-84 
39. Bowman, M.K. and Norrie, J.R. 1982, J.Am.Chem. Soc. 104, pp. 1512-1515

40. a) Höxtermann, E., Werncke, W., stadnich, I.N., Lau, A. and Iloffinann, P. 1932, Stud.Biophys.92, pp. 169-175, b) Höxtermann, E., Werncke, W., Stadnicin, I.N., Lau, A. and Hof fmann, P. 1982, Stud.Biophy. 22, pp. 159-168

41. Pellegring, F., Wong, D., Alfano, R.R., Zilinskas, B. PAB 34, 691-696 (1981).

42. Fried̄ich, J., Scheer, H., Zickendraht-Wendelstadt, B., Haarer, D., J. Chem. Phys. 74, 2260-2266 (1981)

Friedrich,'J., Scheer, H., Zickendraht-Wendelstadt, B., Haarer, D., J. Am. Chøm. S•c. 103, 1030-1035 (1981) Rebane, K.K., Avarmaa R.A., Chem Phys 68(1-2): 191-200, (1982)

43. Pellegrino, F., Wong, D。, Alfano R.R., Zilinskas, B., $\mathrm{PAB} 3 \underline{4}, 691-696$ (1981).

Kobayāshi, T., Degenkolb,E. 0., Behrson, R., Rentzepis, P. M., Maccoll, R., Berns, D. S., Biochemistry 18, $5073(1979)$.

47. Katz, J.J., Norris, J.R., Shipmann, L.S., Thurnauer, M.C., Wasielewski, M.R., Ann. Rev. Biophys. Bioeng. 7, 393$434,(1978)$. 